NUREG / CR-3401

SAND83-1502

R7

Printed September 1983

\title{
Laboratory-Scale Sodium-Carbonate Aggregate Concrete Interactions
}

Henry R. Westrich, Harlan W. Stockman, Ahti Suo-Anttila

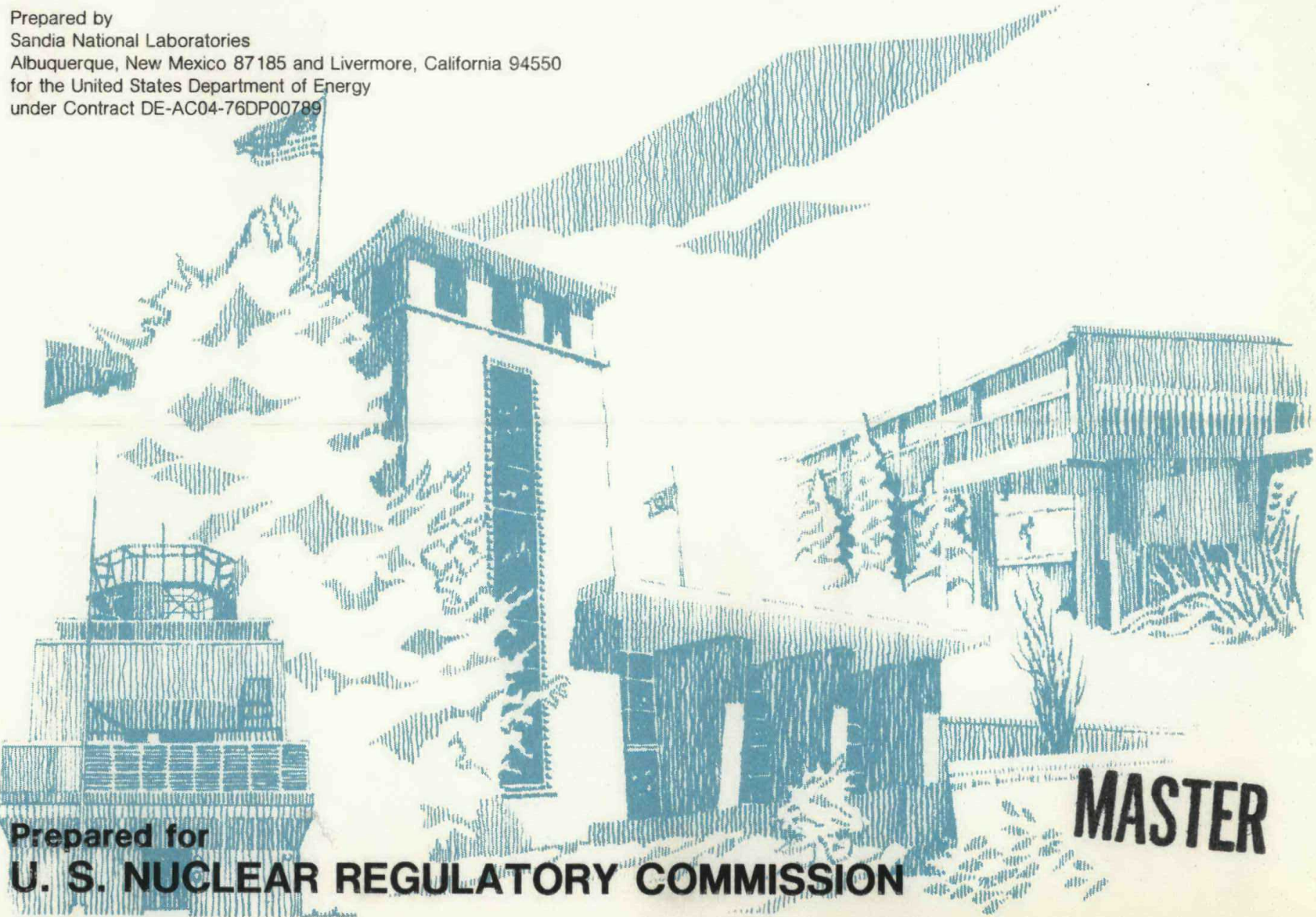




\section{DISCLAIMER}

This report was prepared as an account of work sponsored by an agency of the United States Government. Neither the United States Government nor any agency Thereof, nor any of their employees, makes any warranty, express or implied, or assumes any legal liability or responsibility for the accuracy, completeness, or usefulness of any information, apparatus, product, or process disclosed, or represents that its use would not infringe privately owned rights. Reference herein to any specific commercial product, process, or service by trade name, trademark, manufacturer, or otherwise does not necessarily constitute or imply its endorsement, recommendation, or favoring by the United States Government or any agency thereof. The views and opinions of authors expressed herein do not necessarily state or reflect those of the United States Government or any agency thereof. 


\section{DISCLAIMER}

Portions of this document may be illegible in electronic image products. Images are produced from the best available original document. 


\section{DO NOT MICROFILM
THIS PAGE}

NOTICE

This report was prepared as an account of work sponsored by an agency of the United States Government. Neither the United States Government nor any agency thereof, or any of their employees, makes any warranty, expressed or implied, or assumes any legal liability or responsibility for any third party's use, or the results of such use, of any information, apparatus product or process disclosed in this report, or represents that its use by such third party would not infringe privately owned rights.

Available from

GPO Sales Program

Division of Technical Information and Document Control

U.S. Nuclear Regulatory Commission

Washington, D.C. 20555

and

National Technical Information Service

Springfield, Virginia 22161 
NUREG/CR-3401

SAND8 3-1502

R7

\title{
LABORATORY-SCALE SODIUM-CARBONATE AGGREGATE CONCRETE INTERACTIONS
}

H. R. Westrich

H. W. Stockman

A. Suo-Anttila

Printed: July 1983

Sandia National Laboratories Albuquerque, New Mexico 87185

\author{
Operated by \\ Sandia Corporation \\ for the \\ U. S. Department of Energy
}

\author{
Prepared for \\ Division of Reactor Safety Research \\ Office of Nuclear Regulatory Research \\ U. S. Nuclear Regulatory Commission \\ Washington, DC 20555 \\ Under Memorandum of Understanding DOE 40-550-75 \\ NRC FIN No. Al054
}

\section{DISCLAIMER}

This report was prepared as an account of work sponsored by an agency of the United States Government. Neither the United States Government nor any agency thereof, nor any of their employees, makes any warranty, express or implied, or assumes any legal liability or responsibility for the accuracy, completeness, or usefulness of any information, apparatus, product, or process disclosed, or represents that its use would not infringe privately owned rights. Reference herein to any specific commercial product, process, or service by trade name, trademark, manufacturer, or otherwise does not necessarily constitute or imply its endorsement, recommendation, or favoring by the United States Government or any agency thereof. The views and opinions of authors expressed herein do not necessarily state or reflect those of the United States Government or any agency thereof. 


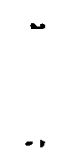




\begin{abstract}
A series of laboratory-scale experiments was made at $600^{\circ} \mathrm{C}$ to identify the important heat-producing chemical reactions between sodium and carbonate aggregate concretes. Reactions between sodium and carbonate aggregate were found to be responsible for the bulk of heat production in sodium-concrete tests. Exothermic reactions were initiated at $580+30^{\circ} \mathrm{C}$ for limestone and dolostone aggregates as well as for hydrated limestone concrete, and at $540 \pm 10^{\circ} \mathrm{C}$ for dehydrated limestone concrete, but were ill-defined for dolostone concrete. Major reaction products included $\mathrm{CaO}, \mathrm{MgO}, \mathrm{Na}_{2} \mathrm{CO}_{3}, \mathrm{Na}_{2} \mathrm{O}, \mathrm{NaOH}$, and elemental carbon. Sodium hydroxide, which forms when water is released from cement phases, causes slow erosion of the concrete with little heat production. The time-temperature profiles of these experiments have been modeled with a simplified version of the SLAM computer code, which has allowed derivation of chemical reaction rate coefficients.
\end{abstract}

$$
\text { iii } /{ }^{\prime \prime}
$$




\section{Table of Contents}

Page

Introduction

Experimental Procedure 3

Results

Discussion

19

Conclusions

References 


\section{List of Tables}

Table

Page

1 Carbonate Concrete Mix Specifications.

2 Bulk Chemical Compositions of Limestone and Dolostone Aggregate and Concrete.

3 Interplanar Spacings Used to Identify Reaction products.

4 Preliminary Sodium-Carbonate Concrete Test Conditions and Results.

5 Controlled Sodium-Carbonate Concrete Test Conditions and Results. 


\section{List of Figures}

\section{Figure}

Page

1 Sample Assembly for Controlled Experiments using a Stainless Steel (SS) Sample Holder.

2 Time-Temperature Profiles for Sodium-Limestone Concrete with Variable Sodium/Concrete Ratios (Given in Parentheses).

3 Time-Temperature Profiles for Sodium Interactions with Limestone Concrete, Aggregate and Portland Type II Cement.

4 Time-Temperature Profiles for Sodium Interactions with coarse and Fine Limestone Aggregate.

5 Time-Temperature Profiles for Sodium Interactions with Hydrated and Dehydrated uimestone Concrete and Portland Type II Cement.

6 Time-Temperature Profiles for Sodium Interactions with Limestone Concrete and Limestone Concrete plus Sodium Hydroxide.

7 Time-Temperature Profiles for sodium Interactions with Iimestone Concrete and Sodium Hydroxide-Coated Limestone Concrete.

8 Time-Temperature profiles for Sodium Interactions with Limestone and Dolostone Concretes.

9 Time-Temperature Profiles for Sodium Interactions with Dolostone Concrete, Aggregate and Dehydrated Concrete.

10 Comparison of Experimental and SLAM-Generated Sodium-Concrete Time-Temperature Profiles for a Sodium/Concrete Ratio $=7.0$.

11 Comparison of Experimental and SLAM-Generated Sodium-Concrete Time-Temperature Profiles for a Sodium/Concrete Ratio $=2.9$. 


\section{List of Figures (Continued)}

\section{Figure}

12 Comparison of Experimental and SLAM-Generated Sodium-Concrete Time-Temperature Profiles for a Sodium/Concrete Ratio $=1.0$.

13 Comparison of Experimental and SLAM-Generated Sodium-Concrete Time-Temperature Profiles for a Sodium/Concrete Ratio $=0.3$.

14 Comparison of Experimental and SLAM-Generated Sodium-Concrete Time-Temperature Profiles for a Sodium/Concrete Ratio $=0.1$.

15 Comparison of Experimental and SLAM-Generated Sodium-Aggregate Time-Temperature Profiles.

16 Comparison of Experimental and SLAM-Generated Sodium-Dehydrated Concrete $\mathrm{T}$ ime-Temperature Profiles.

17 Comparison of Experimental and SLAM-Generated Sodium-Calsium Carbonate Time-Temperature profiles. 


\section{Acknowledgments}

The authors are grateful to E. Randich of Sandia National Laboratories without whose support and critical comments this study would not have been possible. 
Introduction

During a hypothetical core disruptive accident (HCDA) in a liquid metal fast breeder reactor (LMFBR), hot or molten core debris could breach the steel reactor vessel, guard vessel and cavity cell liner, thereby allowing direct contact between the molten sodium coolant and the concrete structural materials in the containment building. Chemical interactions between sodium and concrete would create serious reactor containment hazards such as hydrogen gas generation, chemical heat production and concrete degradation, all of which could adversely affect containment integrity. In order to properly evaluate the consequences of sodium-concrete interactions following a HCDA, the pertinent chemical and engineering data for that reaction process need to be experimentally evaluated. Previous investigations have included sodium-concrete interaction tests with basalt, magnetite, and carbonate (limestone or dolostone) aggregate concretes $(1-6)$. There is general agreement about the mechanism of chemical attack by molten sodium on basalt concrete and magnetite concrete. However, the interaction between sodium and carbonate concretes is not as well understood, even though carbonate concretes are likely to be used in construction of the Clinch River Breeder Reactor (CRBR).

Most investigations of sodium-carbonate concrete interactions have been made through large-scale tests involving $10-450 \mathrm{~kg}$ sodium and $10-5000 \mathrm{~kg}$ concrete $(2,3)$. In a typical large-scale test, molten sodium is poured onto a cast concrete "test article", and allowed to react with the concrete; electric heaters are normally used to maintain the sodium temperature at a minimum set point in the range of $450-850^{\circ} \mathrm{C}$. Thermocouples placed throughout the test article and the sodium pool record temperatures as the reaction progresses and the concrete is eroded. In many cases, exothermic reactions occur which drive concrete and sodium temperatures $10-200^{\circ} \mathrm{C}$ above the set point for several minutes. After maintenance at the set point for up to 100 hours duration, the test is allowed to cool for several days before disassembly and examination. Typically, there is a layer of reaction products between the remaining sodium and unreacted concrete. The chemical and phase compositions of these products together with the gases evolved during a test are the main clues to the sodium-carbonate concrete reactions which have occurred.

Large-scale tests have provided the basic engineering data to predict maximum concrete penetration rates as well as reasonable values for total hydrogen gas generation and heat production when molten sodium reacts with carbonate concrete. 
However, these tests have not provided a coherent picture of the chemical mechanism of concrete attack. In fact, there are conflicting views about the importance of sample geometry, sodium/concrete mass ratio and the presence of sodium hydroxide upon the sodium-carbonate reaction mechanism $(4,5)$. Furthermore, the kinetic and scaling factors essential for extrapolation of large-scale test results to a full-scale LMFBR accident are poorly defined.

The ambiguity of large-scale test results has several sources. First, the large-scale tests are difficult to quench, so it is generally not possible to determine whether a particular reaction product is formed in the first few minutes of the test, after a few hours, or even during the cool-down period (up to several days). The long cool-down period for large-scale tests is particularly serious, because any unreacted concrete can continue to evolve water until the test article cools below $100^{\circ} \mathrm{C}$, and this water can greatly alter the reaction products formed at higher temperatures. Hence, it is difficult to correlate the formation of a particular reaction product with any temperature Eluctuations or high penetration rates observed during the tests. Second, the temperatures of reactions during the tests are not particularly well-defined, because only a limited number of thermocouples can be placed in the test article, and the reaction front may locally bypass individual thermocouples during uneven concrete erosion. And third, the large-scale test results have tended to be somewhat variable, probably because they inherently involve a large number of experimental parameters which are difficult to control by experimenters. Since the large-scale tests are expensive and time-consuming to run, it is not practical to perform large numbers of tests under slightly varied conditions in order to isolate the effects of each experimental variable.

Many of the problems associated with large-scale tests can be circumvented, however, by making smaller, or "laboratory"-scale tests, which involve less than $100 \mathrm{~g}$ of reactants. Reducing the sample mass makes it possible to quench the test articles to room temperature in minutes rather than days, thus minimizing post-test alteration. The temperature of reaction is also more precisely defined because a single thermocouple can be reproducibly positioned in a small volume of sieved and homogenized reactants. In addition, laboratory-scale tests are relatively inexpensive and simple to prepare so that a large number of tests can be performed to evaluate the effects of experimental variables.

This paper reports the results of 58 laboratory-scale experiments which were run to characterize the interaction between molten sodium and limestone and dolostone aggregate 
concretes (hereafter referred to as "carbonate" concretes). The goal of this study is to determine the chemical mechanism of the sodium-carbonate concrete interaction by examining the effects of intrinsic concrete parameters upon that reaction. In this study, the effects of reactant mass ratio, individual concrete components, particle size, water content, aggregate composition and added sodium hydroxide on heat production and reaction kinetics were evaluated. Direct NaOH-carbonate concrete reactions were also examined so as to clarify the role of $\mathrm{NaOH}$ in these reactions. In addition, this study has provided an opportunity to assist in the development of the SLAM (Sodium Limestone Concrete Ablation Model) code (7). The SLAM code is a computer model of sodium-carbonate concrete interactions and contains all of the important phenomena which are believed to occur in sodium-carbonate concrete reactions, including methods for calculating heat generation and system temperatures. Fitting of computer simulations to experimental data allows a determination of kinetic and thermal (heat production) parameters for the chemical reaction model.

\section{Experimental Procedure}

General Procedure

All experiments were made by placing solid sodium and concrete (or concrete component) reactants in nickel crucibles at room temperature and then placing the crucibles in $a$ horizontal tube furnace continuously purged with an inert gas (nitrogen or argon). The furnace was either pre-heated to 600 $\pm 10^{\circ} \mathrm{C}$ prior to insertion of the crucible, or was gradually ramped to $600^{\circ} \mathrm{C}$ after sample insertion to achieve lower heating rates. The temperature rise of the reactants was monitored by a thermocouple which was positioned in the reactants, and the time-temperature data were recorded by computer for later reference. Most time-temperature profiles for sodium-carbonate concrete tests showed a single exothermic peak, or "exotherm," with temperatures rising rapidly above the ambient, followed by gradual cooling to the ambient. For most samples the onset of the exothermic reaction was marked by a sharp inflection in the time-temperature profile, and the threshold temperature could be defined to within $10^{\circ} \mathrm{C}$. All tests were maintained at the ambient for at least 20 minutes before termination. Quenching was achieved within 10-15 minutes by moving the sample out of the furnace and allowing it to cool below the solidification temperature of metallic sodium $\left(97.5^{\circ} \mathrm{C}\right)$ under a stream of inert gas. 
The first part of this study consisted of 36 "preliminary" experiments. In these tests, there was considerable variation in experimental parameters such as sample geometry, aggregate composition and grain size, total sample mass and sodium/concrete (or concrete component) mass ratio, heating rate and inert gas flow. It was found that the chemical products of these experiments, as well as the reaction threshold temperature (the temperature at initiation of the exothermic reaction), were largely independent of total sample mass, sodium/concrete ratio, heating rate, and gas flow. However, the time required for chemical reaction, and the general shapes of the time-temperature profiles were dependent on sample geometry, composition and grain size, sodium/concrete ratio and total sample mass and heating rate. This dependence on experimental conditions made it difficult to extract scale-independent kinetic and thermal parameters from the results of the preliminary experiments.

In order to extract kinetic and thermal parameters, a simplified computer model which describes the main features of sodium-carbonate concrete interactions was used to simulate the experimentally observed time-temperature profiles. This computer model is a part of the larger SLAM code (7), and is described in a later section. Employment of the modified SLAM code required that a new set of 22 experiments, hereafter referred to as "controlled experiments," be designed. These controlled experiments were made at a constant and carefully controlled heating rate, argon flow rate, total sample mass (and crucible mass), and sample geometry. The gas flow rate and the total sample mass were arbitrarily chosen whereas the heating rate was that achieved by rapid insertion of the sample into a preheated furnace. The size of concrete particles used in the controlled experiments was consistent with the size of concrete rubble found in the reaction zone of large-scale tests $(1,8)$. The sodium/concrete (or sodium/concrete component) mass ratio was varied systematically through the controlled experiments and included several "calibration runs" which were used to adjust heat transfer coefficients in the SLAM code. These calibration runs were made by heating various masses of sodium or the reaction products obtained from a previous sodium-concrete reaction with a low sodium/concrete ratio.

A detailed description of the experimental procedure is given below. 
Starting Materials

Two varieties of carbonate concrete which have been proposed for use in construction of CRBR were used in this study, a limestone and a dolostone concrete. The limestone concrete was cast at the Civil Engineering Research Facility of the University of New Mexico using limestone aggregate from the Ralph Rogers, Tennessee quarry, near the CRBR site, while the dolostone concrete was prepared at the Oak Ridge ivational Laboratory using aggregate from the CRBR site quarry. Both concretes were cured for at least 90 days before use in this study. A separate casting of the portland type II cement (no aggregate) was also prepared for comparison with sodium-concrete reactions. Table 1 lists the mix specifications for these concretes while the chemical analyses of the limestone and dolostone aggregate along with their calculated bulk concrete compositions are given in table 2 .

The Iimestone or dolostone concrete used in this study consists of two basic components, $80 \%$ by weight aggregate and $20 \%$ hydrated portland type II cement. The Iimestone aggregate consists of $70 \%$ calcite $\left(\mathrm{CaCO}_{3}\right)$ and $30 \%$ dolomite $\left(\mathrm{CaMg}\left(\mathrm{CO}_{3}\right)_{2}\right)$ while the dolostone aggregate consists of $85 \%$ dolomite and ${ }_{15} \%$ calcite. Some impurities, including quartz and feldspar, have been found in both kinds of aggregate; the proportions of these phases were quite variable between aggregate fragments. Some quartz grains were also found in the cement matrix of the cast concretes. Hydrated Portland type II cement is composed of complex hydrated di- or tricalcium silicates whose composition is roughly $\mathrm{Ca}_{3} \mathrm{Si}_{2} \mathrm{O}_{7} \cdot 3 \mathrm{H}_{2} \mathrm{O}$ (9), where the water content varies depending upon the $\mathrm{Ca} / \mathrm{Si}$ atomic ratio and the extent of hydration (curing length and conditions). A portion of the cement is calcium hydroxide $\left(\mathrm{Ca}(\mathrm{OH})_{2}\right)$ which was also formed during curing. It is evident from table 2 that most of the water in concrete is contained in the cement, either as evaporable water or as structurally bound water. Over half of this water is present in the gel formed by set cement compounds and is released when the concrete is heated above $100^{\circ} \mathrm{C}$. The rest is gradually evolved upon dehydration of simple calcium hydroxide or the more complex hydrated calcium silicates at temperatures ranging from $200-850^{\circ} \mathrm{C}$ (10).

A variety of concrete fragment shapes and sizes were tried in this study. Most preliminary experiments were made with small right cylinders of concrete (15mm diameter by $20-25 \mathrm{~mm}$ long), obtained by coring larger concrete samples; the rest were made with sieved size fractions of crushed aggregate or cement matrix. Most of the controlled experiments were made with $-4+6$ mesh (3.35-4.75mm) concrete, cement, or aggregate fragments, though a few controlled experiments were made with 
smaller Eragments $(-40+60$ mesh, or $0.25-0.35 \mathrm{~mm})$. To prevent selective pulverization of the softer cement component, concrete fragments were prepared by carefully hand-crushing $5 \mathrm{~mm}$ thick slabs cut from larger concrete blocks. All samples were allowed to alr dry before reaction with sodium or sodium hydroxide.

Reagent grade sodium hydroxide, sodium carbonate and silica (Baker) and high purity metallic sodium (RMI Co.) were used in all experiments.

Detailed Procedure for Controlled Experiments

A horizontal resistance tube furnace $17.5 \mathrm{~cm}$ ID $x 80 \mathrm{~cm}$ long) with a $6.0 \mathrm{~cm}$ ID $\times 122 \mathrm{~cm}$ long silica glass liner was employed to heat the samples to $600^{\circ} \mathrm{C}$ in an inert atmosphere of argon with a flow rate of $100 \pm 5 \mathrm{cc} / \mathrm{min}$. The test articles and metallic sodium (solid) were packed in a nickel crucible and a $1 / 16$ inch OD, sheathed chromel-alumel thermocouple was positioned near the bottom of the crucible. A stainless steel holder assembly with a clamp for the thermocouple was employed in order to maintain a constant position of the thermocouple relative to the sample and to facilitate movement of the crucible assembly in and out of the furnace (figure 1). After the thermocouple was in place, a nickel foil lid was crimped on the crucible and the whole assembly was slid into the hot zone of the furnace so as to quickly heat the sample to the ambient furnace temperature. Each run lasted for about 40 minutes; 15 minutes were needed for heatup of the sample while 25 minutes were allowed for thermal and chemical equilibration. Temperatures were monitored every 2-5 seconds and are believed to be accurate to within $10^{\circ} \mathrm{C}$. After reaction, the samples were quenched by sliding the sample assembly to a cool region of the glass liner; when temperatures fell below $85^{\circ} \mathrm{C}$, the samples were removed from the glass tube and stored in an evacuated desiccator containing 'Drierite' (anhydrous $\mathrm{CaSO}_{4}$ ). Selected reaction products were later examined by $x$-ray powder diffraction methods for compound identification and by wet chemistry for bulk composition analyses.

$\mathrm{X}$-Ray Diffraction Procedure.

Crystalline reaction products were identified by $x-r a y$ diffraction. Most diffraction patterns were taken with a powder diffractometer, and the samples were either prepared as thin powder films drifted onto flat glass slides or were packed into plexiglas well slides. Samples which were low in metallic sodium were brittle and could be finely ground; these samples were prepared as drifted slides. However, samples high in metallic sodium were too plastic to grind and were pressed into 
plexiglas well slides. Both drifted and well slides were prepared under argon and were sealed in polyethylene bags with a desiccant $\left(\mathrm{P}_{2} \mathrm{O}_{5}\right.$ or excess sodium) before collection of the diffraction patterns. Generally, the metallic appearance of sodium-rich samples was unaltered throughout data collection, though on humid days, a thin film of sodium hydroxide formed on some samples. A blank was also run on the slide and polyethylene bag for identification of extraneous $x$-ray peaks.

Two sources of error must be recognized in the use of pressed-well slides for $x$-ray diffraction. First, the pressing process may induce preferred orientation, although the relative intensities of the sodium and calcium oxide peaks in the pressed mounts agreed with values given in the literature, suggesting that the pressed samples were randomly oriented. second, the well slide is relatively thick and it is possible that diffraction can occur below the surface of the sample (hence, off the "diffracting circle") causing an apparent shift in the interplanar spacings. To estimate the latter effect, silicon metal was mixed with one sample aso an ibternal standard. The observed shift was less than $0.02 \mathrm{~A}$ at $3 \mathrm{~A}$, and decreased to zero at smaller interplanar spacings. In other samples, it was usually adequate to judge the shift from the diffraction lines of calcium oxide, which occurred in nearly all patterns and were easily identified.

The phases identified with confidence are given in table 3, along with the $x-r a y$ interplanar spacings and intensities most useful for their identification. Several important peaks overlap, which caused some difficulty, but the remaining peaks permitted identification. Several x-ray patterns contained weak lines which could not reasonably be attributed to any compounds listed in the JCPDS $x-r$ ay file. Some samples were $x$-rayed in both a powder diffractometer and in a Debeye-Scherrer camera; the phases identified from the two different geometries were substantially identical. A detailed discussion of the $x$-ray results is given in the results section. These results were obtained from the preliminary as well as the controlled experiments experiments described in this study.

SLAM Computer Code.

The SLAM computer code (7), which is under development at Sandia, is believed to include all of the important phenomena which occur in sodium-carbonate concrete reactions, including a chemical kinetics equation, and methods for calculating heat generation and system temperatures. By making a few slight modifications and simplications, the SLAM code was used to simulate the laboratory scale experiments reported herein. It 
is assumed that the reactants in the crucible are sufficiently well mixed that the system can be modeled as a homogeneous layer. Thus the thermal history of the crucible can be calculated from the following system of equations:

1. Bulk thermal energy equation

2. Chemical kinetics equation

3. Enthalpy equation for heat release or gain

4. Set of assumed chemical reactions

5. Bulk continuity equation for each species

6. Set of thermophysical properties for each species

where "bulk" implies that all of the materials, including the sample holder, are in thermal equilibrium.

The bulk thermal energy equation appears below.

$$
\begin{aligned}
\sum_{i}\left(\rho_{i} c_{i} \delta\right) \frac{\partial T}{\partial t} & =Q_{V} \delta+h_{O A}\left(T_{\infty}-T\right) \\
h_{O A} & =\frac{h_{i} h_{O}}{h_{i}+h_{O}} \\
h_{O} & =h_{\infty}+\frac{\epsilon \sigma\left(T_{\infty}^{4}-T^{4}\right)}{\left(T_{\infty}-T\right)}
\end{aligned}
$$

where

$\begin{array}{ll}\mathrm{h}_{\mathrm{i}} & =\text { internal heat transfer coefficient } \\ \mathrm{h}_{\infty} & =\text { external heat transfer coefficient } \\ \epsilon & =\text { radiative emissivity } \\ \sigma & =\text { Stefan Boltzman constant } \\ \mathrm{T} & =\text { furnace temperature } \\ \sum_{\mathrm{i}} \rho_{\mathrm{i}} \mathrm{C}_{\mathrm{i}} & =\text { sum of material macroscopic density times } \\ \delta & =\text { layer depth }\end{array}$


$\mathrm{T}=$ bulk temperature of the material

$Q_{v} \quad=\quad$ volumetric heat source due to chemical reaction

In this equation, the internal and external heat transfer coefficients were tuned to match, to the extent possible, the three sodium $(10,20$, and $30 \mathrm{~g})$ and the one reaction products (15 g) calibration (heat up) curves. These calibration runs yielded the following values.

$$
\begin{aligned}
\mathrm{h}_{\infty} & =100 \mathrm{~W} / \mathrm{m}^{2} \mathrm{~K} \\
\mathrm{~h}_{i} & =1000 \text { if } a_{\mathrm{Na}}>0.1 \\
& =500 \text { if } a_{\mathrm{Na}}<0.1 \\
\epsilon & =4.5
\end{aligned}
$$

where $a_{\mathrm{Na}}=$ volume fraction of liquid sodium

These numbers are very large because they are simulating the product of heat transfer coefficient times actual surface area per unit area of the layer. That is the reason why exceeds 1 . The equivalent layer depth $\delta$ is found by assuming that all of the materials that are present (including the nickel crucible) exist over a constant area of $0.855 \times 10^{-3} \mathrm{~m}^{2}$. The depth varies in time because the microscopic density of the reactants and products is not the same.

For a general chemical reaction,

$$
a A+b B=c C+d D+\ldots
$$

a chemical kinetics equation of the form

$$
\frac{d x}{d t}=A_{k} e^{-E_{k} / R T}\left(x-\frac{\rho_{A}}{a W_{A}}\right)\left(x-\frac{\rho_{B}}{b W_{B}}\right)
$$

is assumed to apply in SLAM, where $x$ is the amount of reaction that has taken place, $w$ is the molecular weight and $\rho$ is the macroscopic density. The equation states that the rate of 
reaction is proportional to the concentration of the reactants and an Arrhenius temperature coefficient. This equation is solved by implicit finite difference for each chemical reaction.

The heat release (or absorption) due to the chemical reaction can be calculated from the first law of thermodynamics for a chemically reacting system. In the absence of work and heat transfer from the sample assembly, the heat released by a chemical reaction is calculated by the changes in enthalpy of the products less that of the reactants, thus

$$
Q_{v}=\left[\sum_{p} n_{p}\left(H_{f p}+H_{p}\right)-\sum_{r} n_{r}\left(H_{f r}+H_{r}\right)\right] \frac{x^{n+1}}{\Delta t}
$$

where $n_{r}$ is the reactant coefficient, $n_{p}$ is the product coefficient, $\mathrm{H}_{f}$ is the heat of formation of the material at the standard state, $H$ is the actual enthalpy of the material at the reaction temperature with respegct to the standard state, $Q_{y}$ is the volumetric heat source $\left(\mathrm{J} / \mathrm{m}^{3} \mathrm{sec}\right), \mathrm{x}^{\mathrm{n}+1}$ is the end of time step value for the extent of the reaction over the time step size $\Delta t$. Note that in using this equation all enthalpies must be expressed in units of Joules/kg-mole.

The set of chemical reactions in SLAM which are assumed to occur in sodium-carbonate concrete interactions are
a) $\mathrm{H}_{2} \mathrm{O}+\mathrm{Na}=\mathrm{NaOH}+.5 \mathrm{H}_{2}$
b) $4 \mathrm{Na}+3 \mathrm{CaCO}_{3}=2 \mathrm{NaCO}_{3}+3 \mathrm{CaO}+\mathrm{C}$
c) $4 \mathrm{Na}+3 \mathrm{MgCO}_{3}=2 \mathrm{NaCO}_{3}+3 \mathrm{MgO}+\mathrm{C}$
d) $2 \mathrm{NaOH}+\mathrm{CaCO}_{3}=\mathrm{Na}_{2} \mathrm{CO}_{3}+\mathrm{CaO}+\mathrm{H}_{2} \mathrm{O}$
e) $2 \mathrm{NaOH}+\mathrm{SiO}_{2}=\mathrm{Na}_{2} \mathrm{SiO}_{3}+\mathrm{H}_{2} \mathrm{O}$

These reactions are consistent with the reaction products identified for sodium-carbonate concrete experiments with sodium/concrete ratios of about 1.0 (see next section). The sodium-carbonate concrete reaction which yields sodium oxide (see discussion section) was not considered in SLAM because the heat produced, per unit mass of $\mathrm{CaCO}_{3}$, is similar to the reaction with $\mathrm{Na}_{2} \mathrm{CO}_{3}$. Sodium orthosilicate (e.g. $\mathrm{Na}_{4} \mathrm{SiO}_{4}$ ) and other possible reaction products were not considered for two reasons: first, thermophysical and thermochemical properties are not readily available and second, the SLAM code is not currently set up for materials other than those 1 isted. 
Two compositions were used in the SLAM model:

\begin{tabular}{lrr} 
Oxide & \multicolumn{1}{c}{$\underline{\mathrm{A}}$} & \multicolumn{1}{c}{$\underline{\mathrm{B}}$} \\
$\mathrm{CaO}$ & 40.4 & 30.2 \\
$\mathrm{MgO}$ & 5.3 & 11.1 \\
$\mathrm{SiO}_{2}$ & 8.6 & 10.5 \\
$\mathrm{CO}_{2}$ & 37.4 & 35.7 \\
$\mathrm{H}_{2} \mathrm{O}$ & 6.8 & 5.0 \\
Inert & 1.5 & 7.5
\end{tabular}

Composition A is similar to the limestone concrete composition listed in table 2, whereas composition $B$ is more like a dolostone concrete. The time-temperature profiles calculated for the two compostions proved to be nearly indistinguishable, which shows that the SLAM model is not sensitive to compositional variations in the range considered.

In order to apply equations a through $e$, the components $\mathrm{CaO}, \mathrm{MgO}$ and $\mathrm{CO}_{2}$ were assumed to be present as $\mathrm{CaCO}_{3}$ (calcite) and $\mathrm{MgCO}_{3}$ (magnesite), whereas all $\mathrm{SiO}_{2}$ was assumed to be in free silica (quartz), and all $\mathrm{H}_{2} \mathrm{O}$ was assumed to be chemically uncombined water. Realistically, the Mgo would be present in dolomite $\left(\mathrm{CaMg}\left(\mathrm{CO}_{3}\right)_{2}\right)$, and not magnesite. However, the sum of the enthalpies of formation of calcite and magnesite is so similar to the enthalpy of formation of dolomite that little error is incurred by modeling dolomite as a simple binary mixture of $\mathrm{CaCO}_{3}$ and $\mathrm{MgCO}_{3}$, at least in terms of thermal energy yield. It would also be more realistic to treat the $\mathrm{SiO}_{2}$ component as part of $\mathrm{Ca}_{3} \mathrm{Si}_{2} \mathrm{O}_{7}$, rather than as free quartz, since most of the $\mathrm{SiO}_{2}$ in the concrete is in the form of calcium-silicates. Reaction [e] produces about three times as much heat, per formula unit $\mathrm{SiO}_{2}$, as the analogous reaction between $\mathrm{NaOH}$ and $\mathrm{Ca}_{3} \mathrm{Si}_{2} \mathrm{O}_{7}$. However, as will be seen in the results and discussion sections, the $\mathrm{NaOH}^{-\mathrm{SiO}_{2}}$ and $\mathrm{NaOH}-\mathrm{Ca}_{3} \mathrm{Si}_{2} \mathrm{O}_{7}$ reactions are both relatively insignificant producers of heat relative to the $\mathrm{Na}-\mathrm{CaCO}_{3}$ reactions, so the assumption about the physical state of $\mathrm{SiO}_{2}$ is not critical. Overall, the SLAM model could be inproved by choosing a more realistic set of reactions, but the changes would be unlikely to have a great effect on the results. 


\section{Results}

\section{General}

A summary of conditions and results for the preliminary and controlled experiments are given in tables 4 and 5 , respectively. The relative amount of heat produced per unit mass of concrete or concrete component is also given for each test in table 5. These values were calculated by using the average of two $20 \mathrm{~g}$ sodium time-temperature profiles (NACO00, NACO19) as a baseline heating curve; the areal difference between this curve and the test profile was assumed to be a rough measure of the heat produced by that test. The error in the relative heat measurements is estimated to be 5-108 relative, based on the reproducibility of baseline and test profiles. Selected profiles for the controlled experiments are shown in figures 2-7 along with the average $20.0 \mathrm{~g}$ sodium calibration curve as a reference curve. These results point out several important aspects of the sodium-carbonate concrete interaction such as the relative effects of concrete components, reactant mass, water content, particle size, concrete composition and added sodium hydroxide, as will be discussed in the next section.

Preliminary Experiments

In the preliminary experiments, there were several important differences between the results of tests with dolostone concrete, and tests with limestone concrete. In tests with cylindrical samples and sodium/concrete weight ratios of about 0.3-0.5, the limestone concretes consistently produced an exothermic reaction at $550-600^{\circ} \mathrm{C}$ with peak temperatures of about $850^{\circ} \mathrm{C}$, whereas the dolostone concretes simply heated smoothly to the ambient temperature. The limestone cylinders were reduced to a black porous masses containing a few chunks of unreacted aggregate; the dolostone cylinders were coated with a thin black layer of reaction products, but seemed much less altered. A polished section of a dolomite cylinder showed that the cement matrix was partly corroded by the sodium, while the aggregate was almost completely unaltered. Additional tests made with rectangular prisms and irregular pieces of dolomite concrete produced similar results. One test was made with a limestone concrete cylinder and a low sodium/concrete ratio (about 0.1 ); there was still an exothermic reaction at $560^{\circ} \mathrm{C}$, but the peak temperature was only $640^{\circ} \mathrm{C}$, and the cylinder was much less altered than in the other tests with Iimestone concrete cylinders. This limestone concrete cylinder was sectioned and polished, and as 
with the dolostone concrete cylinder, the cement matrix appeared to have been preferentially attacked.

Results similar to those in the sodium-limestone concrete tests were obtained when limestone or dolostone aggregate were reacted with sodium. Both limestone and dolostone samples produced large exothermic peaks with similar threshold temperatures (the temperature at which the exothermic reaction starts). However, both the size and sharpness of the exotherm appeared to be dependent upon the aggregate particle size. Large pieces of aggregate (10-30 $\mathrm{mm}$; $5-8 \mathrm{~g}$ each) showed only small exothermic peaks, with ill-defined threshold temperatures in the range of $565-585^{\circ} \mathrm{C}$. After the experiments, these large aggregate pieces were found to be largely unreacted and were coatea with a thin black reaction layer (1-2 mm thick). Finer Iimestone and dolostone aggregate pieces (from $<0.06$ to $3 \mathrm{~mm}$ diameter) produced much sharper and stronger exothermic peaks, with peak temperatures $r$ ising above $850^{\circ} \mathrm{C}$ and well-defined threshold temperatures in the range $540-565^{\circ} \mathrm{C}$.

In an attempt to evaluate the contribution of hydrated Portland type II cement to the sodium-carbonate concrete reaction, large fragments $(5-8 \mathrm{~mm})$ of hydrated "cement", which had been hand-picked from lightly crushed limestone concrete, were reacted with molten sodium. The temperature rise for these tests was faster than the heatup rate for sodium-carbonate concrete tests. Crushing the sample to less than $0.15 \mathrm{~mm}$ size particles produced little change from the larger sized test results. In both tests, a small exothermic reaction was observed at about $580^{\circ} \mathrm{C}$; however, the "cement" contained very small pieces of $\mathrm{f}$ ine limestone aggregate which would account for the exotherm.

Large fragments $(5-10 \mathrm{~mm})$ of limestone and dolostone concrete and aggregate as well as the hand-picked "cement" matrix were heated in an oven for two hours at a temperature between $670-700^{\circ} \mathrm{C}$. This procedure removed at least $90 \%$ of the water in the cement and aggregate. An x-ray analysis demonstrated that the calcite and dolomite had not decarbonated. These dehydrated samples were then reacted with molten sodium to evaluate the effects of water content upon the sodium-carbonate concrete reaction. In all tests involving dehydrated samples, including the test with dolostone concrete, an exothermic reaction was observed. In the case of the two concretes and "cement", the threshold temperatures were significantly lowered by dehydration $\left(50-75^{\circ} \mathrm{C}\right)$, and the exothermic peaks were considerably sharpened (i.e. a faster exothermic heatup rate and higher peak temperatures). It should be noted that there was little difference between the normal and dehydrated limestone or dolostone aggregate tests, 
but there was a significant difference between the hydrated "cement" (both coarse and fine particles) and the dehydrated "cement".

Tests of direct reaction of sodium hydroxide with both limestone and dolostone concrete and aggregate were made to evaluate the role of $\mathrm{NaOH}$ in the sodium-carbonate concrete reaction mechanism. There was no observable exothermic reaction in any test and the appearence of the reaction products was quite different from that found in the sodium tests. The reaction products included a pale yellow-white "liquid" or slurry which solidified upon cooling and contained varying proportions of aggregate fragments which had not reacted and had settled to the bottom of the crucible. As in the sodium-carbonate concrete tests, the sodium hydroxide-carbonate concrete reaction appeared to have preferentially attacked the cement matrix.

Controlled Experiments

In figure 2, the time-temperature profiles of five sodium-limestone concrete tests are shown relative to the heatup curve for pure sodium. These tests were all made with 3.35-4.75 mm concrete fragments, and differ only by the sodium/concrete mass ratio, maintaining a total mass of 20.0 grams. In general, these curves are very similar to those observed in the preliminary tests. They generally show a rapid temperature increase as the sample assembly is being heated to the ambient furnace temperature, with a single exotherm beginning at about $580^{\circ} \mathrm{C}$. The peak temperature of these exotherms increase with decreasing sodium/concrete ratios until a maximum is reached at a ratio of about 0.3 . However, the amount of heat produced per unit mass of solid reactant reaches a maximum at a sodium/concrete ratio of 1.0 (see table 5). For most tests, the time delay before onset of the exothermic reaction decreases with decreasing sodium/concrete ratios, while their heating rates increase. The test with a sodium/concrete ratio of 0.1 , however, does not follow these trends. In all tests, the relative sharpness of the exothermic peak seems to be inversely correlated to the sodium/concrete ratio.

In order to assess qualitatively the relative contribution of the principle components of concrete upon the overall sodium-carbonate concrete reaction, separate samples of coarse $(3.35-4.75 \mathrm{~mm}$ ) hydrated portland type II cement (prepared without aggregate) and limestone aggregate were reacted with sodium. These results are shown in figure 3 where they are compared against a sodium-carbonate concrete profile. Both the cement and aggregate reactions produce equivalent amounts of 
heat per unit mass (within error of measurement). Since carbonate aggregate is four times as abundant as cement in the concrete, and since the shapes of the sodium-aggregate and sodium-concrete profiles are similar, the sodium-limestone aggregate reactions probably account for the bulk of the overall heat production in the sodium-carbonate concrete tests. However, in the first few minutes, the sodium-cement test heats much more rapidly than either the sodium-concrete or sodium-aggregate test, and sodium-cement reactions are probably the most important heat-producers in the early stages of the sodium-carbonate concrete interaction.

The heatup rate and delay time for sodium-aggregate reactions appears to be dependent upon particle size; use of a smaller size fraction (0.25-0.42 vs. 3.35-4.75 mm) decreases this thermal lag relative to the larger fragments (figure 4). Use of smaller aggregate particles also leads to more complete reaction as evidenced by slight increase in the relative amount of heat produced and the lack of unreacted aggregate pieces in the sodium pool after the test.

The contribution of water-related reactions to the total sodium-concrete heat production can be evaluated by comparison of the heatup curves for sodium-limestone concrete and sodium-hydrated Portland type II cement with those curves for dehydrated limestone concrete and cement (figure 5; samples were dehydrated at $670^{\circ} \mathrm{C}$ for 2 hours without any evidence of decarbonation). Up to about $535^{\circ} \mathrm{C}$, the heatup rate is higher for the hydrous concrete and cement. Beyond that temperature, the dehydrated samples exhibit sharper exothermic peaks, lower threshold temperatures and higher peak temperatures. Both hydrated and dehydrated concretes produce equivalent amounts of heat per unit mass although the presence of water in the samples seem to moderate or slow the rate of exothermic reactions.

In two tests, sodium hydroxide was added to the reactants in order to evaluate its role in the general sodium-carbonate concrete attack mechanism when sodium is also present. In test NACO07, the starting materials consisted of a mixture of sodium, Iimestone concrete, and $\mathrm{NaOH}$ pellets. The time-temperature profile for this test is shown in figure 6 , along with the profile for a test with sodium and the same amount of concrete, but no $\mathrm{NaOH.} \mathrm{For} \mathrm{test} \mathrm{(NACO07),} \mathrm{the}$ addition of $\mathrm{NaOH}$ did not affect the amount of heat produced, but did broaden the exotherm, lower the peak temperature, and increase the heat-up rate in the first few minutes of the test. In test NACO08, the concrete pieces were coated with molten $\mathrm{NaOH}$ at $350^{\circ} \mathrm{C}$, allowed to cool to $30^{\circ} \mathrm{C}$, then reacted with sodium as in previous tests. In figure 7, the time-temperature 
profile for NACOO8 is compared with the profile for a test containing sodium and the same amount of concrete, but no added $\mathrm{NaOH}$. Coating the concrete with $\mathrm{NaOH}$ has reduced the amount of heat produced by about $30 \%$ relative to the test without added $\mathrm{NaOH}$, and has also dramatically broadened the exotherm and lowered the maximum reaction temperature.

Reaction of $3.35-4.75 \mathrm{~mm}$ size fragments of dolostone concrete (in contrast to the larger 10-30 $\mathrm{mm}$ pieces in preliminary tests) with molten sodium produced results similar to those found for sodium-limestone concrete tests. Both heating profiles are compared in figure 8 ; the major difference between the two is that the exotherm from the dolostone test is broad without a clearly defined threshold temperature, while the limestone concrete exotherm is sharp and has a distinct threshold temperature. As in the case of limestone concrete, the sodium-aggregate reaction is probably responsible for the bulk of the heat observed for dolostone concrete (figure 9). Reducing the size of the dolostone aggregate to less than 0.25 $\mathrm{mm}$ fragments further defines the exothermic peak. A faster thermal response was also obtained using dolostone concrete which had been heated at $670^{\circ} \mathrm{C}$ for two hours prior to reaction with sodium (figure 9). As with dehydrated limestone concrete, the exothermic reaction was initiated at a lower temperature $\left(\sim 520^{\circ} \mathrm{C}\right)$ which is about $15^{\circ} \mathrm{C}$ less than the threshold temperature for the limestone test.

Analyses of Reaction Products

The reaction products identified by $x$-ray diffraction methods in the experiments between sodium and carbonate concrete were metallic sodium, CaO, Mgo (for dolostone concrete), $\mathrm{Na}_{4} \mathrm{SiO}_{4}, \mathrm{Na}_{2} \mathrm{SiO}_{3}$, varied amounts of $\mathrm{Na}_{2} \mathrm{CO}_{3}$ and $\mathrm{Na}_{2} \mathrm{O}$, and elemental carbon. Sodium hydroxide was observed to some degree in all sodium-concrete runs but may have resulted from the formation of a very thin hydroxide layer on the sample surface during post-test handling becaues of brief exposure to the atmosphere. Little or no sodium remained in the products of runs with sodium/concrete ratios $<0.3$. It was also found that $\mathrm{Na}_{2} \mathrm{O} / \mathrm{Na}_{2} \mathrm{CO}_{3}$ ratios were highest in those runs with an initial sodium/concrete ratio >1.0. The variation in the amounts of sodium silicates was somewhat random, and may result from a non-uniform distribution of quartz and feldspar grains in the starting material. It is also possible that the sodium silicates are nearly amorphous in some samples, and do not appear in the diffraction patterns. Elemental carbon probably accounts for the blackness of the products, but was not observed in the $x$-ray patterns, probably due to poor crystallinity. 
The crystaline products observed in tests with natural carbonate aggregate and sodium, and an additional run with roagent grade calcium carbonate (NACO18) and sodium, were CaO, MgO (for dolomite aggregate), $\mathrm{Na}_{2} \mathrm{O}$, and $\mathrm{Na}_{2} \mathrm{CO}_{3}$. The products of one test were dissolved in a $10 \%$ solution of hydrochloric acid and the black flocculant residue was filtered off. This black material, which amounted to about two weight percent of the reaction products, was ignited and identified as carbon via $\mathrm{CO}_{2}$ analysis although $\mathrm{x}$-ray analysis had showed it to be amorphous.

In those preliminary tests where limestone and dolostone concrete were reacted with sodium hydroxide, the reaction products were identified as $\mathrm{NaOH}, \mathrm{Na}_{2} \mathrm{CO}_{3}, \mathrm{Na}_{4} \mathrm{SiO}_{4}$ and $\mathrm{CaO}$ (and $\mathrm{MgO})$. For the test where the concrete was coated with $\mathrm{NaOH}$ before addition of sodium (NACO08), the reaction products were $\mathrm{CaO}, \mathrm{Na}_{4} \mathrm{SiO}_{4}$, and $\mathrm{Na}_{2} \mathrm{CO}_{3}$; no $\mathrm{NaOH}$ remained.

In one run with sodium and hydrated portland type II cement (NACO09), all major peaks in the $x$-ray pattern could be assigned to $\mathrm{CaO}, \mathrm{NaOH}$, and $\mathrm{Na}_{2} \mathrm{O}$. Because metallic sodium in the $x$-ray mount remained fresh in appearance throughout data collection, the $\mathrm{NaOH}$ is thought to be real rather than an artifact of sample preparation. Four very small peaks in the $x-r a y$ spectrum match the strongest lines for $\mathrm{Na}_{2} \mathrm{SiO}_{3}$ and $\mathrm{Na}_{4} \mathrm{SiO}_{4}$, but overall, there is remarkably little evidence for crystalline silicates. It is possible that the reaction products contain sodium-calcium silicates which are nearly amorphous and diffract poorly. The reaction products from a preliminary test between sodium and reagent grade silica were identified by $x$-ray diffraction to be sodium and $\mathrm{Na}_{2} \mathrm{SiO}_{3}$. The formation of $\mathrm{Na}_{2} \mathrm{SiO}_{3}$ requires that some reduced phase, such as silicon metal or Na-Si alloys, be produced to balance the reaction; however, there was no evidence for such a phase in the diffraction patterns.

During the sodium-concrete and sodium-aggregate reactions, aerosols were produced and condensed in several regions of the silica tube. The condensed material in the cooler region of the tube was white and identified by $x$-ray diffraction as $\mathrm{Na}_{2} \mathrm{CO}_{3}$ while the aerosols deposited in the hot spot of the tube were black and are thought to be carbon.

SLAM-Generated Time-Temperature Profiles

Selected time-temperature profiles pertinent to the controlled sodium-limestone concrete tests were simulated using the modified SLAM computer code. The sodium (NACO00,19,20,21) and the reaction product (obtained by reheating NACO05) calibration curves were used to adjust heat transfer 
coefficients in the SLAM code for a more realistic calculation of the sodium-concrete heating curves. The profiles of the simulated sodium-concrete tests are compared to their experimental profiles in figures 10 through 14 . It is evident that, except for one test (NACO06), the experimental and calculated heating curves are in remarkably good agreement when comparing peak size, shape, threshold temperature, and delay time before the onset of the exotherm. Only when the sodium/concrete ratio is low (0.1), is there a significant difference between the two curves. For the test with a low sodium/concrete ratio, there is much more heat generated than predicted by the SLAM code, although the time delay, exotherm shape and threshold temperature are very similar.

Three other experimental heating curves were also compared with SLAM-generated curves (Eigures 15-17); they include sodium reactions with limestone aggregate, dehydrated limestone concrete and pure calcium carbonate. In general, there is good agreement between calculated and experimental heating curves, although there are some differences. In particular, the experimental heatup curve for coarse $(3.35-4.75 \mathrm{~mm})$ and fine (0.25-0.42 mm) limestone aggregate (figure 15) is shifted to the right. Reducing the aggregate grain size brings the experimental heatup curve to closer agreement with the simulated one. The heat produced from the simulated exotherm is approximately equivalent to that of the fine aggregate as is its general shape; the heat generated from the coarse aggregate test is about $10 \%$ less, which may not be a significant difference, given the errors in measurement.

The experimental sodium-dehydrated limestone concrete curve (figure 16) also exhibited a slight thermal lag relative to the calculated curve. In addition, the experimental curve has a threshold temperature which is significantly lower than the calculated one $\left(2535\right.$ versus $\left.\sim 600^{\circ} \mathrm{C}\right)$. The profiles for the sodium-calcium carbonate reaction are given in figure 17, where the experimental $r u n$ is observed to heat up at a slightly faster rate than the calculated curve. All the other features between the two curves are fairly similar. It should be noted that the carbonate used in this test was very fined grained $(<3.0 \mu \mathrm{m})$ relative to other tests and appears to affect reaction kinetics. This effect has not been experimentally evaluated in this study and therefore has not been included in the SLAM code.

From these experiments, the following constants were derived (i.e gave the "best" correlation with experimental results) for the reaction of sodium and limestone concrete: 


$$
\begin{aligned}
& \mathrm{Na}+\mathrm{CaCO}_{3} \quad \mathrm{E}_{\mathrm{k}}=2.5 \times 10^{8} \text { (J/kg mole) } \\
& \text { and } \\
& \mathrm{Na}+\mathrm{MgCO}_{3} \\
& A_{k}=8.85 \times 10^{12}\left(\mathrm{~m}^{3} / \mathrm{kg} \text { mole sec }\right) \text { if } a_{N a}<0.6 \\
& A_{k}=8.85 \times 10^{11}\left(\mathrm{~m}^{3} / \mathrm{kg} \text { mole sec }\right) \text { if } a_{\mathrm{Na}}>0.6 \\
& \text { where } a_{\mathrm{Na}}=\text { sodium volume fraction } \\
& \text { and } A_{k} e^{-E_{k} / R T} \leq 0.1 \\
& \mathrm{NaOH}+\mathrm{CaCO}_{3} \quad \mathrm{E}_{\mathrm{k}}=1.4 \times 10^{8}(\mathrm{~J} / \mathrm{kg} \mathrm{mole}) \\
& A_{k}=3.0 \times 10^{6}\left(\mathrm{~m}^{3} / \mathrm{kg} \text { mole } \mathrm{sec}\right) \\
& \mathrm{NaOH}+\mathrm{SiO} 2 \\
& E_{k}=1.4 \times 10^{8}(\mathrm{~J} / \mathrm{kg} \text { mole }) \\
& A_{k}=3.0 \times 10^{6}\left(\mathrm{~m}^{3} / \mathrm{kg} \text { mole sec }\right)
\end{aligned}
$$

\section{Discussion}

Laboratory-Scale Tests

In this section, several chemical reactions will be outlined which provide a consistent description of the laboratory-scale test results as they apply to sodium-carbonate concrete interactions. For simplicity, the limestone aggregate will be assumed to be pure $\mathrm{CaCO}_{3}$ (i.e. no dolomite component). In addition, discussion of the effect of dolomite upon sodium-carbonate concrete reactions will be kept to a minimum because of unresolved experimental problems with reaction rates and a paucity of reliable thermochemical data for dolomite. A11 thermodynamic data have been taken from Barin and others (11) who provide the most complete data set for sodium compounds. The enthalpy and Gibbs energy of reaction $\left(\Delta \mathrm{H}_{\mathrm{r}}\right.$ and $\left.\Delta G_{r}\right)$ were calculated at 800 or $1100 \mathrm{~K}\left(527\right.$ or $\left.827^{\circ} \mathrm{C}\right)$ because this is the temperature range over which the critical reactions seem to occur. Care should be taken, however, when interpreting or extrapolating some of the conclusions presented below because thermodynamic uncertainties and scaling factors are unknown and could be significant.

Consideration of the reaction products formed during sodium-carbonate concrete, sodium-carbonate aggregate, and sodium-calcium carbonate tests as well as the fact that aggregate comprises about $80 \%$ by weight of the concrete, suggest that there are two competing reactions between sodium and calcium carbonate which are responsible for most of the heat produced in sodium-carbonate interactions (figures 2-7). The chemical mechanism for this interaction appears to vary as 
a function of the maximum temperature attained by the sample or perhaps because of the initial sodium-concrete ratio used in that test. In those tests where the sodium-concrete ratio was high (see figure 2), the maximum exothermic peak temperature was relatively low, and based upon $x-r a y$ analyses, the following reaction appears dominant,

$$
4 \mathrm{Na}+\mathrm{CaCO}_{3}=2 \mathrm{Na}_{2} \mathrm{O}+\mathrm{CaO}+\mathrm{C}
$$

with a $\Delta \mathrm{H}_{r}(800 \mathrm{~K})=-65.1 \mathrm{kcal}$ and $\mathrm{a} \Delta \mathrm{G}_{\mathrm{r}}(800 \mathrm{~K})=-41.2 \mathrm{kcal}$. On the other hand, in those tests where the sodium/concrete ratio was low, the peak temperature was considerably higher and the following reaction predominates,

$$
4 \mathrm{Na}+3 \mathrm{CaCO}_{3}=2 \mathrm{Na}_{2} \mathrm{CO}_{3}+3 \mathrm{CaO}+\mathrm{C}
$$

where $\Delta H_{r}(1100 \mathrm{~K})=-126.9 \mathrm{kcal}$ and $\Delta \mathrm{G}_{\mathrm{r}}(1100 \mathrm{~K})=-109.3 \mathrm{kcal}$. The transition from reaction [1] to [2] as a function of temperature is feasible according to

$$
4 \mathrm{Na}+\mathrm{Na}_{2} \mathrm{CO}_{3}=3 \mathrm{Na}_{2} \mathrm{O}+\mathrm{C}
$$

where the Gibbs energy of reaction at $800 \mathrm{~K}$ is $-4.5 \mathrm{kcal}$ and at $1100 \mathrm{~K}$ is $+5.8 \mathrm{kcal}$. These calculations indicate that sodium oxide is thermodynamically preferred at the low reaction temperatures found in the sodium-concrete tests with high sodium/concrete ratios while sodium carbonate appears to be the stable phase at higher temperatures. However, given that the $G$ for reaction [3] is small and the overall uncertainty for the tabulated thermochemical data is of the same magnitude, either compound could be the stable phase in these tests.

To test the validity of equation [2], the $\mathrm{Na}_{2} \mathrm{CO}_{3} / \mathrm{CaO}$ weight ratio was estimated for the products of experiment NACO04. This experiment was chosen because of its low initial sodium/concrete ratio, and because $x$-ray patterns of the reaction products showed no evidence of $\mathrm{Na}_{2} \mathrm{O}$. The $\mathrm{Na}_{2} \mathrm{CO}_{3} / \mathrm{CaO}$ ratio was estimated from $x$-ray patterns by measuring the area ratio of the $2.96 \mathrm{~A} \mathrm{Na}{ }_{2} \mathrm{CO}_{3}$ peak to the $2.40 \mathrm{~A}$ Cao peak, and comparing it with the area ratio for a synthetic CaO-Na ${ }_{2} \mathrm{CO}_{3}$ standard of known composition. The $\mathrm{Na}_{2} \mathrm{CO}_{3} / \mathrm{CaO}$ ratio thus obtained for the NACOO4 products was $0.86+0.09$, compared to 1.26 calculated from equation [2]. This discrepancy may arise from the loss of some $\mathrm{Na}_{2} \mathrm{CO}_{3}$ as an aerosol, from additional CaO present in the cement matrix as a dehydration product of calcium hydroxide, or from partial decarbonation of the aggregate prior to reaction with sodium. In some runs, thermocouple temperatures exceeded the 1 atm dissociation temperature of calcite (about $900^{\circ} \mathrm{C}$ ), and the actual temperatures at reacting grain boundaries may have been much 
higher than those recorded by the thermocouple. One would expect $\mathrm{CO}_{2}$ liberated by calcite dissociation to react with souium, but with a sufficiently small pathlength, some $\mathrm{CO}_{2}$ might escape. In some runs, small aggregate particles appeared to be floating on the sodium surface, which would facilitate loss of $\mathrm{CO}_{2}$.

The water evolved from concrete upon heating will exothermically react with molten sodium according to

$$
\mathrm{Na}+\mathrm{H}_{2} \mathrm{O}=\mathrm{NaOH}+.5 \mathrm{H}_{2}
$$

where $\Delta \mathrm{H}_{\mathrm{r}}(800 \mathrm{~K})=-42.5 \mathrm{kcal}$. This reaction also accounts for hydrogen gas generation and sodium hydroxide production during sodium-carbonate concrete tests $(2,3)$. The excess heat generated by the sodium-water reaction appears to be responsible for the faster heatup during the early stages of those tests bearing hydrous samples. This effect is more pronounced for tests with a lower sodium/concrete ratio (figure 2) or for those tests using hydrated cement (figure 3). Aggregate samples which contain little water (figure 4), and dehydrated concrete or cement samples (figure 5) do not exhibit this effect but have a thermal response similar to that of pure sodium (i.e. heating only by conduction). In fact, dehydration of concrete and cement before reaction with sodium resulted in a reduction of exothermic heat of approximately 15 and $60 \%$, respectively, relative to the hydrated samples (see table 5). These results point out the fact that, in laboratory-scale tests, reaction [4] is not an important heat producer for sodium-carbonate reactions because concrete does not contain much water (<8\%; see table 1$)$. However, the sodium-water reaction can be a major source of heat in large-scale sodium-carbonate concrete tests because water, released from unreacted concrete, can react with sodium long after the initial exothermic reaction has subsided.

The presence of water in 1 imestone and dolostone concrete also seems to affect the kinetics of sodium-carbonate reactions as evidenced by the relative shape of the exotherm as well as its threshold temperature for those tests involving hydrated and dehydrated carbonate concretes. For example, the exotherms observed in the dehydrated limestone and dolostone concrete tests were sharper (i.e. faster exothermic heatup and higher peak temperature) and had lower threshold temperatures than the exotherms developed in the hydrated concrete test. These effects, observed in tests using dehydrated samples, could be explained if the concrete and cement samples had developed cracks upon heating, resulting in a substantial increase of surface area to enhance sodium reactions. However, the results of several preliminary tests show that an increase in surface 
area alone is inadequate to explain the differences between hydrated and dehydrated samples. In preliminary sodium-hydrated "cement" tests, both the coarse and the fine $(4.0 \mathrm{vs} .<0.2 \mathrm{~mm})$ sized fragments yielded nearly identical time-temperature profiles, while dehydrated, coarse "cement" fragments produced very different results (exotherm was sharper with a lower threshold temperature). Hence, the effect of dehydration appears to be due to the absence of water and not to an increase of surface area. These results demonstrate that the presence of water in concrete mitigates the reaction process and inhibits its onset. It should be noted, however, that use of a smaller particle size as well as substitution of dolostone aggregate in the concrete also affects the kinetics of sodium-carbonate concrete reactions as evidenced by changes in the shape of the exothermic peak between coarse and fine limestone aggregate tests (figure 4) and limestone and dolostone concrete tests (figure 8 ).

Production of sodium hydroxide from reaction [4] can also result in chemical attack upon aggregate by the following reaction,

$$
2 \mathrm{NaOH}(\mathrm{liq})+\mathrm{CaCO}_{3}=\mathrm{Na}_{2} \mathrm{CO}_{3}+\mathrm{CaO}+\mathrm{H}_{2} \mathrm{O}
$$

which is slightly endothermic at both $800 \mathrm{~K}\left(\Delta \mathrm{H}_{\mathrm{r}}=+4.2 \mathrm{kcal}\right)$ and $1100 \mathrm{~K}\left(\Delta \mathrm{H}_{\mathrm{r}}=+2.4 \mathrm{kcal}\right)$. In reality, the $\Delta \mathrm{H}$ will be somewhat different because the activities of $\mathrm{NaOH}$ and $\mathrm{Na}_{2} \mathrm{CO}_{3}$ will be lowered by their mutual solubilities. It has been suggested by Sallach and others (12) that the attack of sodium hydroxide upon calcium carbonate is necessary for the large exothermic reaction accompanying concrete penetration. However, this reaction mechanism has not been confirmed in this study. In fact, direct sodium hydroxide-carbonate concrete and aggregate tests yielded smooth heatup curves with no evidence of large exothermic reactions (table 4). This was also confirmed in a later controlled test (NACO08) where fragments of limestone concrete were reacted with sodium hydroxide at $350^{\circ} \mathrm{C}$ (well below the threshold temperature), cooled to $30^{\circ} \mathrm{C}$, and then reacted with sodium at $600^{\circ} \mathrm{C}$. In this test, there was no exothermic heat produced from reaction [4] because most of the water in the concrete had evaporated before addition of sodium. This test also yielded $30 \%$ less heat than did the sodium-carbonate concrete test (NACO03); some of the heat loss was probably due to the pre-test treatment of the carbonate concrete with sodium hydroxide (reaction [5]). Furthermore, the exothermic peak was considerably broader than either the exotherm in the sdoium-carbonate test or the sodium-carbonate concrete test with added sodium hydroxide (NACO07) which suggests that a layer of either sodium hydroxide or its 
reaction products from equation reactions.

[5] inhibit sodium-carbonate

It is important to note that the reaction of aggregate or cement with sodium hydroxide or sodium produces compounds which are stable relative to these reactive compounds. Buildup of these stable reaction products provide a means to inhibit or completely arrest direct sodium-carbonate concrete reactions by limiting mass transport of sodium to unreacted concrete. This effect was also evident for several sodium-carbonate concrete tests (preliminary and NACO07) where the interiors of larger fragments of aggregate were unreacted and were separated from metallic sodium by a layer of reaction products. The presence of a similar boundary layer in large-scale tests has been previously suggested as a mechanism to protect unreacted concrete from further attack and penetration by sodium $(2,4,5)$. Discuption of this "protective" reaction product/sodium hydroxide layer by cracking, particulate settling or gas bubbling or its penetration by sodium diffusion or permeation would allow additional sodium-concrete reactions to occur until either the reactants were exhausted or migration of reactants through the boundary layer became infinitely slow.

Some of the reaction products from the sodium-Portland type II cement tests were difficult to identify. They included calcium oxide and one or more sodium silicates $\left(\mathrm{Na}_{2} \mathrm{SiO}_{3}\right.$, $\mathrm{Na}_{4} \mathrm{SiO}_{4}$ or perhaps $\mathrm{Na}_{2} \mathrm{CaSiO}_{4}$ ). The presence of some calcium oxide is due to the dehydration of calcium hydroxide upon heating while the remainder could be the result of an exothermic reaction between sodium oxide and anhydrous calcium silicate. These reactions, however, are not very important to overall heat production in sodium-concrete interactions because of the small proportion of cement in concrete.

The reaction products from sodium-dolostone concrete tests suggest that equations analogous to [1] and [2] may be written for sodium-dolostone interactions. The enthalpies for these reactions are calculated to be only 10-15\% greater per mole of sodium consumed than the analogous limestone reactions although it is difficult to confirm on the basis of the experimental results presented in this study. No reason is given for the broad exothermic peak observed in sodium-dolostone concrete reactions relative to the sodium-limestone concrete exotherm (see figure 8), although possible explanations include concrete variability between the Iimestone and dolostone concretes cast at oak Ridge and Sandia Laboratories, or perhaps there are inherent differences between calcite and dolomite which affects the kinetics of sodium-carbonate concrete reactions. 
Other laboratory-scale tests with sodium and carbonate aggregate concrete have produced results qualitatively similar to those reported in this study $(13,14)$. It has generally been shown that there is a threshold temperature, between 500 and $600^{\circ} \mathrm{C}$, below which carbonate concrete does not significantly react with molten sodium, at least within the time frame of laboratory-scale tests. The reaction products reported in other studies, however, vary considerably; although much of the reported variation may not be real, but rather may reflect the difficulties in sample preparation and $x-r a y$ diffraction analysis: Hudswell and others (15) report $\mathrm{Na}_{2} \mathrm{CO}_{3}{ }^{\circ} \mathrm{H}_{2} \mathrm{O}, \mathrm{Na}_{2} \mathrm{SiO}_{3}$ ' and $\mathrm{Na}_{6} \mathrm{Si}_{2} \mathrm{O}_{7} \cdot \mathrm{H}_{2} \mathrm{O}$ as reaction products; they argue that the hydrated phases existed as such at reaction temperatures, but as their sample preparation and $x$-ray data collection were done partly in air, it seems likely that the hydration is an artifact. Hudswell and others do note that some hydration may have occurred during the long cooldown period. Barker and Gadd (16) report $\mathrm{CaO}, \mathrm{Na}_{2} \mathrm{O}, \mathrm{Na}_{2} \mathrm{SiO}_{3}, \mathrm{Na}_{4} \mathrm{SiO}_{4}, \mathrm{NaOH}$ and sodium-calcium silicates as reaction products between sodium and the separate components of carbonate concretes at $400-600^{\circ} \mathrm{C}$, though there is some uncertainty as to whether $\mathrm{Na}_{2} \mathrm{O}$ was actually observed in diffraction patterns. They argue that $\mathrm{Na}_{2} \mathrm{O}$ was not observed in the products of some sodium-limestone reactions because it "reacts with $\mathrm{SiO}_{2}$ present in the aggregate to form $\mathrm{Na}_{4} \mathrm{SiO}_{4}$ " Given the reactions proposed by Barker and Gadd, the originall limestone would have to be greater than $37 \%$ by weight $\mathrm{SiO}_{2}$ to transform all the $\mathrm{Na}_{2} \mathrm{O}$ in their tests to $\mathrm{Na}_{4} \mathrm{SiO}_{4}$; this seems unlikely. They also report that sodium-carbonate aggregate reactions produce $2.4-4.0$ times as much heat per unit mass as sodium-Portland cement reactions, whereas the present study suggests that the sodium-cement and carbonate aggregate reactions produce similar amounts of heat per unit mass. This discrepancy is probably due to the experimental procedure used by Barker and Gadd, where the samples are mixed with molten sodium at $120^{\circ} \mathrm{C}$ before insertion into the DTA apparatus. All of the evaporable water would have reacted with sodium prior to measurement of reaction enthalpies at higher temperatures, yielding a relatively low enthalpy value for cement. Chasanov and Staahl (17) report CaO, Mgo, $\mathrm{Na}_{6} \mathrm{Si}_{2} \mathrm{O}_{7} \cdot 1 \mathrm{lH}_{2} \mathrm{O}$, elemental carbon and minor amounts of $\mathrm{Na}_{2} \mathrm{CO}_{3}$ as reaction products between carbonate concrete and molten sodium at $500^{\circ} \mathrm{C}$. However, excess sodium was removed from the samples prior to $x-r a y$ analysis by washing with butyl alcohol; this treatment would have also dissolved $\mathrm{NaOH}$ and $\mathrm{Na}_{2} \mathrm{O}$, and perhaps $\mathrm{Na}_{2} \mathrm{CO}_{3}$. Again, the sodium silicate may have hydrated upon exposure to air, resulting in incorrect identification of post-test alteration products as primary sodium-concrete reaction products. Inless special precautions are taken to 
minimize exposure of the reaction products to air, moisture or reactive organic solvents, the true nature of these sodium compounds will be lost during post-test hydration or oxidation.

Comparisons with Large-Scale Tests

There are several important similarities and differences between the results of the laboratory scale tests outlined above, and large-scale tests employing 5 to $450 \mathrm{~kg}$ sodium and 5 to $5000 \mathrm{~kg}$ of carbonate aggregate concrete. Some of the large-scale tests showed no sign of exothermic reactions, but generally, tests with ambient temperatures above the threshold temperature of about $550^{\circ} \mathrm{C}$ produced exothermic peaks anywhere from 2 minutes to several hours into the test $(2,3)$. The reaction products observed after dismantling of the large-scale tests have included $\mathrm{CaO}, \mathrm{Na}_{2} \mathrm{CO}_{3}, \mathrm{NaOH}$ and elemental carbon. The amount of carbon observed has varied from $11 \%$ (2) to less than 0.18 by weight (8). The larger amounts of carbon are consistent with direct reactions between sodium and calcium carbonate, which are thought to occur in laboratory-scale tests, while the smaller amounts of carbon suggest that much of the $\mathrm{CaO}$ and $\mathrm{Na}_{2} \mathrm{CO}_{3}$ was produced by reaction of $\mathrm{NaOH}$ with $\mathrm{CaCO}_{3}$. The fraction of $\mathrm{NaOH}$ in the products is much greater in the large-scale tests. This is to be expected, as the amount of $\mathrm{NaOH}$ produced in the laboratory-scale tests is limited by the amount of water in the reacting concrete, whereas in the large-scale tests, water is added to the reaction zone as the underlying concrete dehydrates. No sodium oxide has been reported with certainty in the larger scale tests; however, $\mathrm{Na}_{2} \mathrm{O}$ may have been hydrated by water released from unreacted concrete during the long cool-down periods typical of large-scale tests (up to 3 days). Furthermore, post-test alteration, including hydration and NaOH-reactions, as well as the variability of large-scale test results, have prevented experimental verification of the presence of a "protective" layer of reaction products by which direct sodium-carbonate concrete reactions are limited $(2,4,5)$. The results of these laboratory-scale experiments provide support to this theory.

A major difficulty in the interpretation of large scale tests lies in determining when the NaOH-rich reaction layer forms. The formation of the NaOH-rich layer is important, as it may prevent, or at least mitigate, direct reactions between sodium and concrete, and make the results of laboratory-scale tests inapplicable. Decanted tests, such as HEDL test SC-3 (1), show that a NaOH-rich layer had formed after 8 hours of reaction. The segregation of $\mathrm{NaOH}$ into a separate layer may have taken several hours, because the solubility of NaOH in sodium is about 15 weight percent at $600^{\circ} \mathrm{C}$ (18) and maximum water release rates from concrete would be $\leq 1 \mathrm{~kg} / \mathrm{hr} \mathrm{m}^{2}$ (10). 
Given a $100 \mathrm{~kg}$ sodium pool at $600^{\circ} \mathrm{C}$, over a $1 \mathrm{~m}^{2}$ concrete surface, roughly 7 hours of combined water release and reaction with sodium would be required before reaching saturation with NaOH. This calculation is approximate and ignores the possibility that a NaOH layer may form at the concrete-sodium interface faster than it can be dissolved into the sodium. However, the calculation does illustrate that the exothermic reactions which occur in the first few minutes of the larger scale tests are probably direct reactions between sodium and concrete, without a significant amount of $\mathrm{NaOH}$ acting as a flux or mass transport medium.

SLAM Model.

In general, it was possible to achieve good fits between SLAM-generated time-temperture profiles and the experimental profiles. However, a tew SLAM-generated heating profiles display a lag relative to the experimental profiles which cannot be accounted for by experimental error in the calibration tests. This time delay is believed to be caused by thermal equilibration problems and is most evident for the sodium-Iimestone aggregate or dehydrated limestone concrete tests (figures 15 and 16). This lag is attributed to the low thermal conductivity of the concrete or aggregate. Thus, the thermocouple response, which measures sodium temperature, rises more rapidly at first because there is less effective mass to heat, and slower later because the dehydrated concrete or the nearly anhydrous aggregate is then heating up. The computer calculation, however, keeps the entire system in thermal equilibrium.

The calculated and experimental heating curves for sodium-concrete interactions seem to match very well when the sodium/concrete ratio is $\geq 0.3$; with less sodium, the SLAM code predicted a lower exothermic peak temperature than was actually observed. There is also a significant lag in the heating rate and the delay time for the experimental exotherm relative to the simulated one as well as a difference in peak temperatures. It should be noted, however, that when the sodium/concrete ratio $\leq 0.3$, there is not enough sodium to completely cover the concrete fragments and certainly not enough for complete reaction of the limestone concrete. The most likely explanation for these discrepancies is that the water is not treated properly in the modified SLAM code. In the experiments, the water is released slowly as a function of temperature while in the simulation, the water is present as an initial condition and therefore reacts immediately, consuming a significant fraction of the sodium. Thus, less sodium is available to react with carbonate when the threshold temperature is finally reached. A calculation with no water 
reaction $\left(A_{k}\right.$ of water $=0$ ) results in a thermal history which is identical to the experimental curve. The water reaction problem does not occur with higher sodium/concrete ratios because there is significantly less water present.

The test containing pure calcium carbonate is an unusual situation wherein the experimental heating curve has $r$ isen at a faster rate than the calculated one (figure 17). In this test, the calcium carbonate grain size averaged less than $3.0 \mu \mathrm{m}$ in diameter and would allow for thermal equilibration with the sodium. The small particle size would dramatically increase the surface area avalable for reaction, whereupon the chemical kinetics of sodium-carbonate reactions would be affected. The kinetic coefficients used to model this test were derived from the tests using large-sized $(3.35-4.75 \mathrm{~mm})$ limestone concrete fragments, and are probably inappropriate. The dependence of $A_{k}$ and $E_{k}$ upon particle size is unknown, and was not evaluated in this study.

The kinetic coefficients that were derived for these simulations were not single valued but gave the best correlation with experimental results when the pre-exponential coefficient $A_{k}$ (for sodium-carbonate reactions) was allowed to depend upon the sodium volume function. The reason for this might be the transition from the sodium-calcium carbonate reaction [1] yielding sodium oxide at low temperatures (which are sodium rich) to the sodium poor reaction [2] at higher temperatures. Transitional chemical reactions are not included in the SLAM code because significantly more complex numerical methods would be required. The impact of this modeling deficiency upon the predicted results is minimal as can be seen by comparison with the experiments.

The kinetic coefficients for the sodium hydroxide reactions are of unknown accuracy because $\mathrm{NaOH}$ was present in such small concentrations that the thermal energy yield was negligible when compared to the sodium-calcium carbonate reactions.

It appears that the chemical kinetics model used in the SLAM code is a suitable one for assessing the relative effects of reactant mass and concrete components in these reactions, provided that the effects of aggregate composition and particle size are not considered. The driving force of macroscopic molar density divided by the reaction coefficient seems to be an appropriate quantity because the full range of sodium density could be correlated. There is a discrepancy, however, at the low end of sodium concentration attributable to water release effects not accounted for in the modified SLAM code. 


\section{Conclusions}

The laboratory investigation of sodium-concrete interactions has helped to define some of the important chemical reactions which occur at the reaction interface. unlike many previous tests, the experimental design and the analytical procedure used in this study have permitted identification of reaction products with minimal chemical alteration during post-test cooldown or pre-analysis treatment. The results of this study have shown that:

1. Direct reaction of sodium and carbonate aggregate is responsible for the large exothermic peak which is characteristic of sodium-carbonate concrete reactions above the threshold temperature. This reaction is thought to occur during the initial stage of rapid concrete penetration and produces either sodium carbonate or sodium oxide along with calcium oxide and elemental carbon, depending upon the initial mass ratio of sodium and concrete or the temperature of the reaction; at high sodium/concrete ratios llow temperatures), sodium oxide is favored and at lower sodium/concrete ratios (high temperatures), sodium carbonate is produced.

2. Water released from concrete exothermically reacts with sodium yielding sodium hydroxide which can then act as a fluxing agent for additional concrete erosion with little or no additional heat production.

3. Formation of sodium hydroxide as well as the reaction products from sodium- or sodium hydroxide-carbonate concrete interactions inhibit further sodium-carbonate concrete reactions, apparently by limiting mass transport of sodium to unreacted concrete.

4. The kinetics of sodium-concrete interactions, as evidenced by the sharpness of the exothermic peak and the threshold temperature, is severely dependent upon particle size in sodium-dolostone concrete tests and upon total water content for both sodium-limestone and dolostone concrete reactions.

5. The chemical kinetics model in the SLAM computer code appears appropriate for prediction of the laboratory scale test results, although different chemical reactions and kinetics models could be incorporated into the SLAM code so as to more accurately describe sodium-carbonate concrete interactions. Additional 
scaling parameters and kinetic factors need to be incorporated into the SLAM code so as to account for the effects of particle size and aggregate composition upon sodium-carbonate concrete interactions which were observed in this study. 


\section{References}

1. J.A. Hassberger, Intermediate $\frac{\text { Scale }}{\text { Ranford }}$ Engineering $\frac{\text { Sodium-Concrete }}{\text { Development }}$ Laboratory, HEDL-TME 77-99, 1978.

2. A.K. Postma, L.D. Muhlestein and R.P. Colburn, $\underline{A}$ Review of Sodium-Concrete Reactions, Hanford Engineering Development Laboratory, HEDL-TME 81-7, 1981.

3. E. Randich, J.E. Smaardyk and R.U. Acton, Large-Scale Exploratory Tests of Sodium/Limestone Concrete Interactions, sandia National Laboratories, NUREG/CR-3000, SAND82-2315, 1982.

4. D.G. Swanson and J.N. Castle, Review of the Interaction of Sodium with Concrete and other Materials, Brookhaven National Laboratory, Tas $\overline{k l}$ Report to the NRC, 1982.

5. L.D. Muhlestein and A.K. Postma, Sodium-Concrete Reaction Executive Summary Report: Application to Limestone Concrete, Hanford Engineering Development Laboratory, HEDL-TME 82-15, 1982.

6. E. Randich and R.U. Acton, Large-Scale Exploratory Tests of Sodium/ Magnetite Concrete Interactions, sandia National Laboratories, NUREG/CR-3189, SAND83-0356, 1982.

7. A.J. Suo-Anttila, SLAM = A Sodium-Limestone concrete

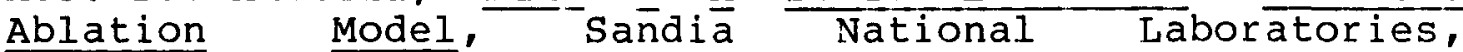
NUREG/CR -3379, SAND83-7114, 1983.

8. E. Randich and R.U. Acton, Intermediate-Scale Tests of Sodium Interactions with Calcite and Dolomite Aggregate Concretes, Sandia National Laboratories, NUREG/CR-3288, SAND83-1064, 1983.

9. F.M. Lea, The Chemistry of Cement and Concrete, (London: Edward Arnold Publishers, 1970), pp 727 . 
10. J.D. MCCormack, A.K. Postma and J.A. Schur, Water Evolution from Heated Concrete, Hanford Engineering Development Laboratory, HEDL-TME 78-87, 1979.

11. I. Barin, O. Knacke and 0. Kubaschewski, Thermochemical Properties of Inorganic Substances, (New York: Springer-Verlag, $197 \overline{7}$ ), pp 921 .

12. R.A. Sallach, J.E. Smaardyk and D.L. King, "Chemical Phenomenology of the Sodium/Limestone Concrete Interactions," Trans. Am. Nucl. Soc., Vol 28, pp 522-23 (1978).

13. S.A. Mecham, The Interactions of Tennessee Limestone Aggregate Concrete with Liquid Sodium, Westinghouse Electric corp., WARD-D-0141, 1976.

14. R.E. Witkowski, R.G. Charles and C.L. Jones, A Chemical Investigation of Sodium-Concrete Reactions, Westinghouse Research Laboratory, Report Number 77-8B6-NACON-Rl, 1977.

15. F. Hudswell, J.C. Waldron, M.A. Jones, P.T. Moseley and S.W. Sanderson, The Interaction of Sodium with Various Concretes, with Limited Access, at 400 to $600^{\circ} \mathrm{C}, \frac{\text { Atomic }}{\mathrm{AER}}$ Energy Research Establishment, Report Number $\overline{A E R E}-\mathrm{R}-6708$, 1971 .

16. M.G. Barker and P.G. Gadd, "A Chemical study of the Sodium-Concrete Reaction," Proc. LMFBR Safety Topical Mtg., Lyon, France, pp 91-107 (1982).

17. M.G. Chasanov and G.E. Staahl,Sr., "High Temperature Sodium-Concrete Interactions," Jour. Nuclear Materials, Vol 66, pp 217-20 (1977).

18. E.M. Mitkevish and B.A. Shikhov, "Study of the System $2 \mathrm{Na}$ $+\mathrm{NaOH}=\mathrm{Na}_{2} \mathrm{O}+\mathrm{NaH}, "$ Russian Jour. Inorg. Chem., Vol 11, no. 3, pp 346-49 (1966). 
Table 1. Concrete Mix Specifications

Material

Weight Percent

Limestone

Dolostone

\begin{tabular}{lrr}
\hline Aggregate & 79.7 & 78.8 \\
Cement Type II & 12.0 & 10.3 \\
Water & 6.3 & 7.5 \\
Flyash * & 2.0 & 3.4 \\
Admixture* & $<0.1$ & $<0.1$
\end{tabular}

* Includes both air-entraining and water reducing agents.

Table 2. Bulk Chemical Compositions of Limestone and Dolostone Aggregate and Concrete*.

Dxide

Limestone

Dolostone

Aggregate Concrete Aggregate Concrete

\begin{tabular}{lrrrr}
\hline $\mathrm{CaO}$ & 43.6 & 42.6 & 29.4 & 30.0 \\
$\mathrm{MgO}$ & 6.6 & 5.6 & 18.2 & 14.6 \\
$\mathrm{Fe}_{2} \mathrm{O}_{3}$ & 0.3 & 0.8 & 0.6 & 1.3 \\
$\mathrm{SiO}_{2}$ & 5.0 & 8.5 & 11.0 & 13.6 \\
$\mathrm{Al}_{2} \mathrm{O}_{3}$ & $\mathrm{na}$ & $<0.4$ & $\mathrm{na}$ & $<0.2$ \\
$\mathrm{Na}_{2} \mathrm{O}_{2}$ & $\mathrm{na}$ & $<0.3$ & $\mathrm{na}$ & $<0.3$ \\
$\mathrm{KO}_{3}$ & 0.4 & 6.7 & 0.4 & 8.0 \\
$\mathrm{H}_{2}$ & 43.0 & 34.3 & 42.0 & 33.1 \\
$\mathrm{CO}_{2}$ & & & &
\end{tabular}

* Calculated using Table 1 and the average compositions for flyash ** and Portland type II cement from Lea (9). not anaylyzed. 


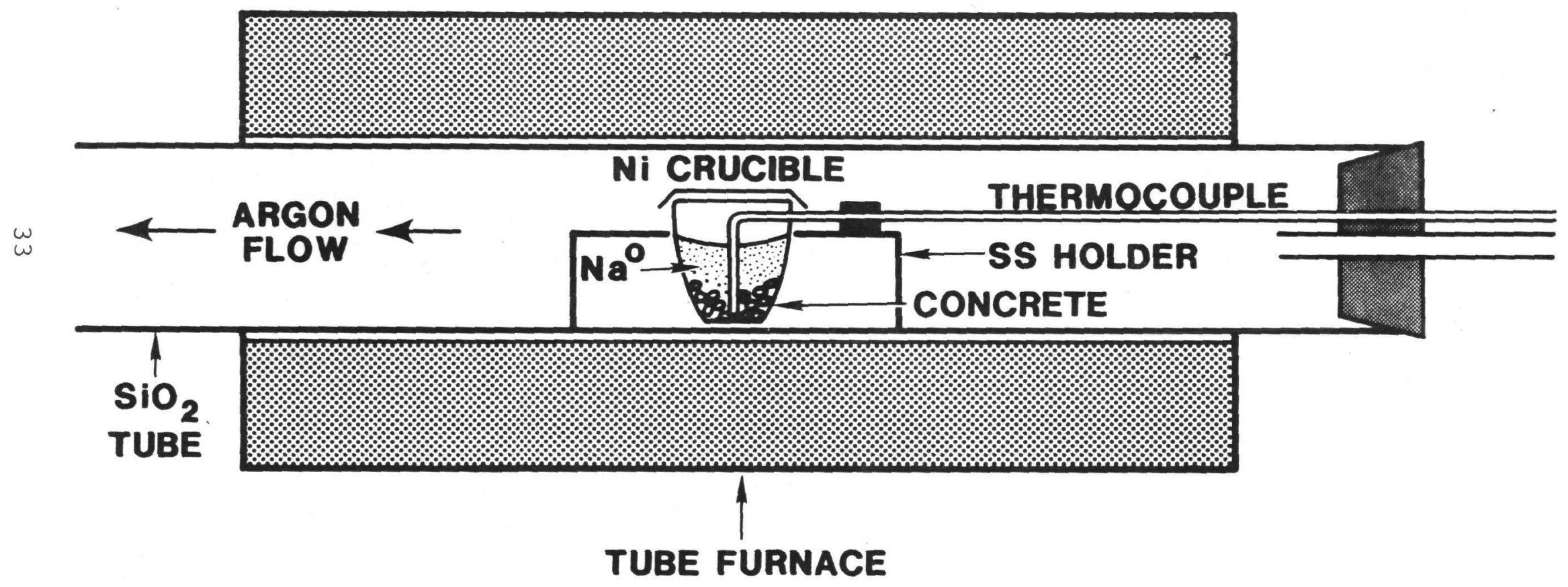

Figure 1. Sample Assembly for Controlled Experiments Using a Stainless steel (SS) Sample Holder. 
Table 3. Interplanar Spacings Used to Identify Reaction Products*

\begin{tabular}{|c|c|c|c|c|}
\hline $\mathrm{Na}{ }^{\star \star}$ & $\mathrm{Na}$ & $\mathrm{Na}_{2} \mathrm{O}$ & $\mathrm{Na}_{2} \mathrm{CO}_{3}$ & $\mathrm{Na}_{2} \mathrm{CO}_{3}$ \\
\hline $1-850$ & $22-948$ & $3-1074$ & $18-1208$ & this study \\
\hline $\begin{array}{l}3.02(100) \\
2.13(15) \\
1.75(20) \\
1.51(5) \\
1.36(5) \\
1.25(3) \\
1.15(3)\end{array}$ & $\begin{array}{l}3.034(100) \\
2.146(15) \\
1.752(23) \\
1.517(5) \\
1.357(6) \\
1.239(1) \\
1.147(4) \\
1.011(2)\end{array}$ & $\begin{array}{l}3.19(40) \\
2.76(40) \\
1.95(100) \\
1.67(10) \\
1.60(20) \\
1.39(30) \\
1.27(5) \\
1.24(20) \\
1.13(30) \\
1.07(5) \\
0.98(20) \\
\text { and } \\
\text { others }\end{array}$ & $\begin{array}{l}3.43(16) \\
3.28(18) \\
2.97(100) \\
2.72(30) \\
2.62(40) \\
2.61(45) \\
2.55(65) \\
2.37(100) \\
2.34(10) \\
2.26(50) \\
2.20(35) \\
2.04(12) \\
1.96(35) \\
1.93(6) \\
1.89(30) \\
1.71(40) \\
1.68(14)\end{array}$ & $\begin{array}{l}3.40(3) \\
3.21(5) \\
2.954(100) \\
2.700(14) \\
2.611(15) \\
2.589(14) \\
2.359(46) \\
2.249(19) \\
2.187(14) \\
2.170(19) \\
2.027(3) \\
1.947(8) \\
1.881(14) \\
1.706(3) \\
1.675(3)\end{array}$ \\
\hline $\mathrm{NaOH}$ & $\mathrm{Na}_{2} \mathrm{SiO}_{3}$ & $\mathrm{Na}_{4} \mathrm{SiO}_{4}$ & $\mathrm{CaO}$ & $\mathrm{MgO}$ \\
\hline $1-1173$ & $16-818$ & $27-783$ & $4-0777$ & $4-0829$ \\
\hline $\begin{array}{l}5.8(13) \\
2.85(20) \\
2.35(100) \\
2.03(10) \\
1.90(8) \\
1.70(30) \\
1.65(25) \\
1.46(10) \\
1.35(2) \\
1.27(5)\end{array}$ & $\begin{array}{l}5.26(40) \\
3.56(40) \\
3.04(100) \\
2.570(45) \\
2.412(50) \\
1.889(25) \\
1.756(25) \\
1.450(10) \\
1.419(25)\end{array}$ & $\begin{array}{l}4.86(70) \\
4.41(50) \\
3.77(60) \\
3.50(50) \\
3.49(60) \\
2.668(70) \\
2.622(70) \\
2.571(80) \\
2.481(50) \\
2.317(80) \\
2.276(100) \\
2.210(50) \\
2.168(80) \\
2.114(60) \\
2.012(60) \\
1.887(50) \\
\text { and } \\
\text { others }\end{array}$ & $\begin{array}{l}2.778(34) \\
2.405(100) \\
1.701(45) \\
1.451(10) \\
1.390(5) \\
1.203(4) \\
1.104(4) \\
\text { and } \\
\text { others }\end{array}$ & $\begin{array}{l}2.431(10) \\
2.106(100) \\
1.489(52) \\
1.270(4) \\
1.053(5) \\
0.967(2) \\
0.942(17) \\
\text { and } \\
\text { others }\end{array}$ \\
\hline
\end{tabular}

* Interplanar spacings in Angstroms; relative intensities given in parentheses.

"JCPDS file number. "This study" refers to a $\mathrm{Na}_{2} \mathrm{CO}_{3}$ sample which had been fused at $950^{\circ} \mathrm{C}$; spacings and intensities were measured on a powder diffractometer. 
Table 4. Preliminary Sodium-Carbonate Concrete Test Conditions and Results

Reactants*

Number Sodium/Concrete Threshold of Tests Ratio Temperature $\left({ }^{\circ} \mathrm{C}\right)$

\begin{tabular}{|c|c|c|}
\hline $\mathrm{Na}$ & + & Is Conc** \\
\hline $\mathrm{Na}$ & + & Ls Agg \\
\hline $\mathrm{Na}$ & + & Ls Agg $(<3 \mathrm{~mm})$ \\
\hline $\mathrm{Na}$ & + & DI Conc \\
\hline $\mathrm{Na}$ & + & Dl Agg \\
\hline $\mathrm{Na}$ & + & DI Agg $(<3 \mathrm{~mm})$ \\
\hline iva & + & "Cem" ( $4 \mathrm{~mm})$ \\
\hline $\mathrm{Na}$ & + & "Cem" $\quad(<.2 \mathrm{~mm})$ \\
\hline $\mathrm{Na}$ & + & Dhd Is Conc \\
\hline $\mathrm{Na}$ & + & Dhd Ls Agg $(.3-.4 \mathrm{~mm})$ \\
\hline $\mathrm{Na}$ & + & Dhd DI Conc \\
\hline $\mathrm{Na}$ & + & Dhd DI Agg $(.3-.4 \mathrm{~mm})$ \\
\hline $\mathrm{Na}$ & + & Dhd "Cem" $(<.2 \mathrm{~mm})$ \\
\hline $\mathrm{Na}$ & + & Qtz $(<.1 \mathrm{~mm})$ \\
\hline $\mathrm{NaOH}$ & + & Is Conc \\
\hline $\mathrm{NaOH}$ & + & Ls Agg $(<3 \mathrm{~mm})$ \\
\hline $\mathrm{NaOH}$ & + & DI Conc \\
\hline $\mathrm{NaOH}$ & + & DI Agg $(<3 \mathrm{~mm})$ \\
\hline
\end{tabular}
$0.1-0.5$
0.4
0.5
$0.4-0.5$
$0.4-0.5$
0.5
0.5
0.6
0.5
0.5
$0.5-1.0$
0.5
0.5
2.5
0.7
0.5
$0.5-1.0$
1.0

* Includes cylinders or fragments between $10-30 \mathrm{~mm}$ (long dimension) unless noted otherwise.

* Symbols: Na=metallic sodium; NaOH=sodium hydroxide; Ls=1imestone; Conc=concrete; Agg=aggregate; $\mathrm{DI}=$ dolostone; "Cem"=cement matrix From Iimestone concrete; Qtz=quartz; Dhd=dehydrated; $w=w e a k$ exothermic reaction; $n=$ no exothermic reaction; 
Table 5. Controlled Sodium-Carbonate Concrete Test Conditions and Results

$\begin{array}{ccc}\text { Test } & \text { Reactants } & \text { Sodium/Concrete Threshold } \\ \text { ID } & (\mathrm{g}) & \text { Ratio Relatiłf }\end{array}$

\begin{tabular}{|c|c|c|c|c|c|c|}
\hline NACOOO & $20.0 \mathrm{Na}$ & & & - & - & - \\
\hline NACOOI & $17.5 \mathrm{Na}$ & 2.5 & Ls Conc & 7.0 & $595 \pm 10$ & 4.8 \\
\hline $\mathrm{NACOO} 2$ & $14.9 \mathrm{Na}$ & +5.1 & Ls Conc & 2.9 & $565 \pm 10$ & 5.9 \\
\hline $\mathrm{NACO} 03$ & $10.0 \mathrm{Na}$ & +10.0 & Ls Conc & 1.0 & $580 \pm 10$ & 7.5 \\
\hline NACOO 4 & $4.6 \mathrm{Na}$ & +15.6 & Ls Conc & 0.3 & $560 \pm 10$ & 6.2 \\
\hline NACOO 5 & $5.0 \mathrm{Na}$ & +15.0 & Ls Conc & 0.3 & $595 \pm 10$ & $\mathrm{~nm}$ \\
\hline NACOO 6 & $2.5 \mathrm{Na}$ & +17.5 & Ls Conc & 0.1 & $570 \pm 10$ & 3.5 \\
\hline \multirow{2}{*}{$\mathrm{NACOO} 7$} & $10.0 \mathrm{Na}$ & +5.0 & Ls Conc & & & \\
\hline & & 5.0 & $\mathrm{NaOH}$ & - & $605 \pm 10$ & 6.0 \\
\hline NACO0 8 & $\begin{array}{r}5.1 \mathrm{Na} \\
(5.0\end{array}$ & $\begin{array}{l}+ \\
+10.0\end{array}$ & Is concl \# & - & $525+10$ & 52 \\
\hline NACOO9 & $15.0 \mathrm{Na}$ & $\begin{array}{r}10.0 \\
+\quad 5.1\end{array}$ & Cem & - & $540+20$ & $\begin{array}{l}3.2 \\
4.9\end{array}$ \\
\hline NACOIO & $15.0 \mathrm{Na}$ & 5.0 & Ls Agg & - & $575 \pm 10$ & 4.6 \\
\hline NACOII & $15.0 \mathrm{Na}$ & 5.1 & Ls Agg (f)" & - & $575 \mp 10$ & 4.9 \\
\hline $\mathrm{NACO} 12$ & $14.9 \mathrm{Na}$ & 5.0 & Ls çonc ${ }^{+}$ & 3.0 & $540 \pm 10$ & 5.0 \\
\hline $\mathrm{NACO} 13$ & $15.0 \mathrm{Na}$ & +5.0 & $\mathrm{Cem}^{+}$ & - & $515+10$ & 1.8 \\
\hline NACO 14 & $10.3 \mathrm{Na}$ & +10.2 & Dl Conc & 1.0 & $585+20^{\prime}$ & 8.4 \\
\hline NACO15 & $10.0 \mathrm{Na}$ & +10.0 & Dl Agg & - & $565 \pm 15$ & 5.7 \\
\hline NACOló & $10.0 \mathrm{Na}$ & +10.0 & Dl Agg(f)" & - & $575 \pm 10$ & 3.5 \\
\hline $\mathrm{NACO} 17$ & $10.2 \mathrm{Na}$ & +10.0 & D1 Conc ${ }^{+}$ & 1.0 & $530 \pm 10$ & 5.8 \\
\hline NACO 18 & $15.0 \mathrm{Na}$ & +5.0 & $C C^{\# \#}$ & - & $545 \pm 10$ & 5.9 \\
\hline NACOI9 & $20.0 \mathrm{Na}$ & & & - & - & - \\
\hline NACO 20 & $10.3 \mathrm{Na}$ & & & - & - & - \\
\hline $\mathrm{NACO} 21$ & $30.5 \mathrm{Na}$ & & & - & - & - \\
\hline
\end{tabular}

Symbols: Na=metallic sodium; NaOH=sodium hydroxide; Ls=limestone; $\mathrm{Dl}=$ dolostone; Conc=concrete; Cem=Portland type II cement;

Agg=aggregate; CC=calcium carbonate; nm=not measured. Arbitrary units of heat per gram mass of concrete or concrete component

\# Coated with sodium hydroxide at $350^{\circ} \mathrm{C}$ and then cooled to $30^{\circ} \mathrm{C}$ before addition of sodium.

"Fragment size is between 0.25 and $0.42 \mathrm{~mm}$.

+ Heated at $670^{\circ} \mathrm{C}$ for 2 hours; $x$-ray analysis indicates no decarbonation.

\# Slow and gradual exothermic reaction.

\#\# Fine grained $(<3.0 \mathrm{\mu m})$ reagent grade $\mathrm{CaCO}_{3}$. 


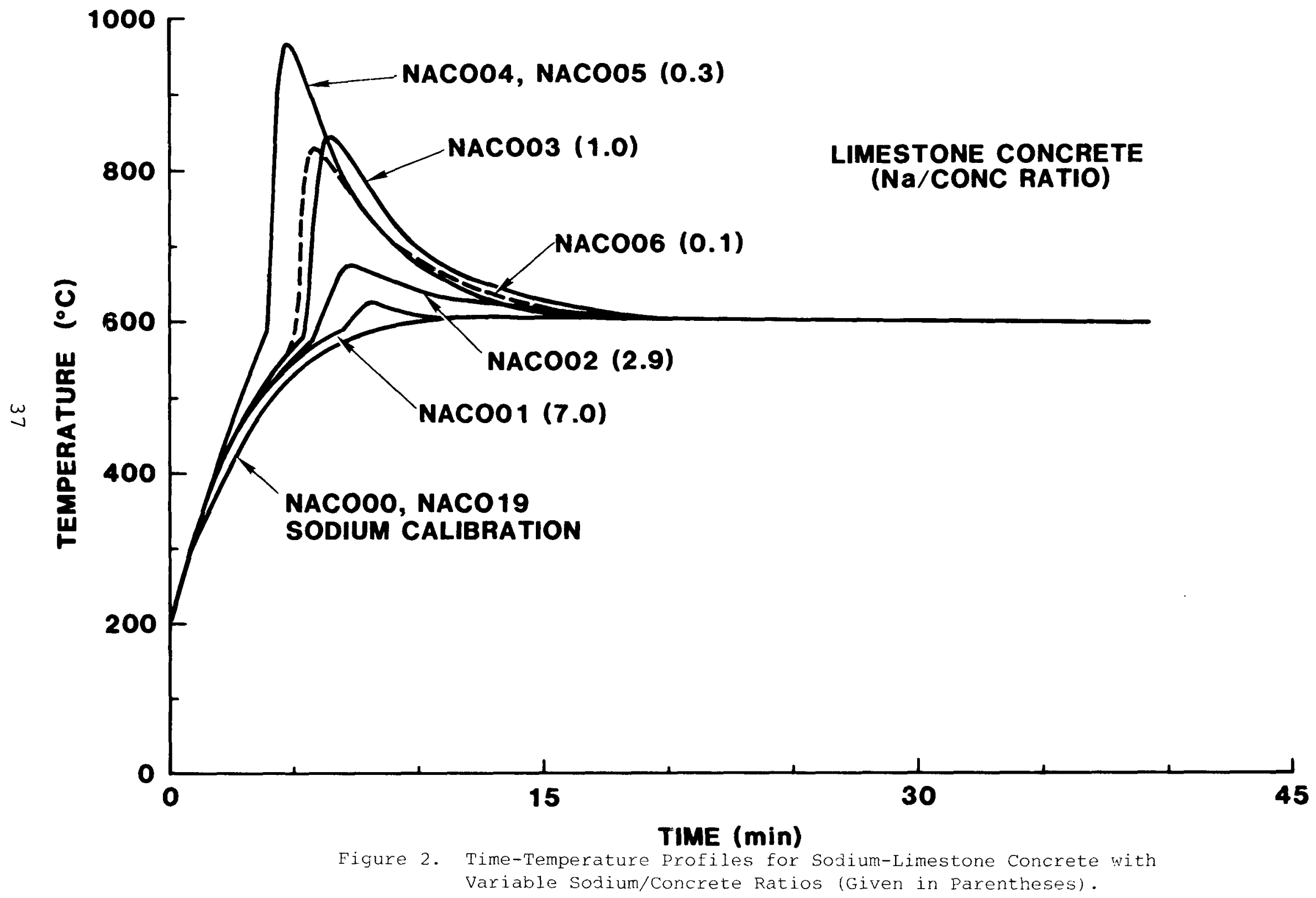




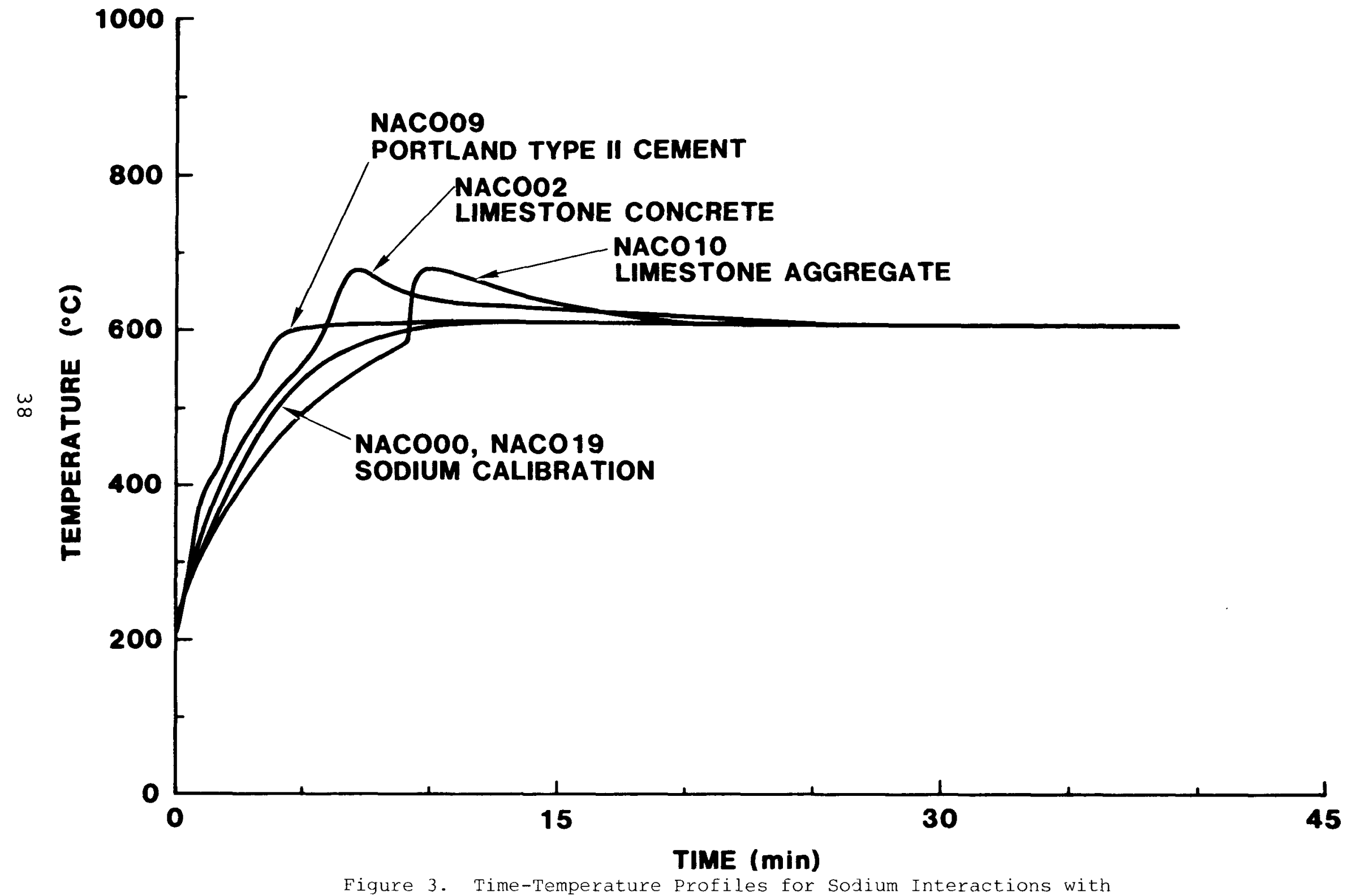

Figure 3. Time-Temperature Profiles for Sodium Interactions with

Limestone Concrete, Aggregate and Portland Type II Cement. 


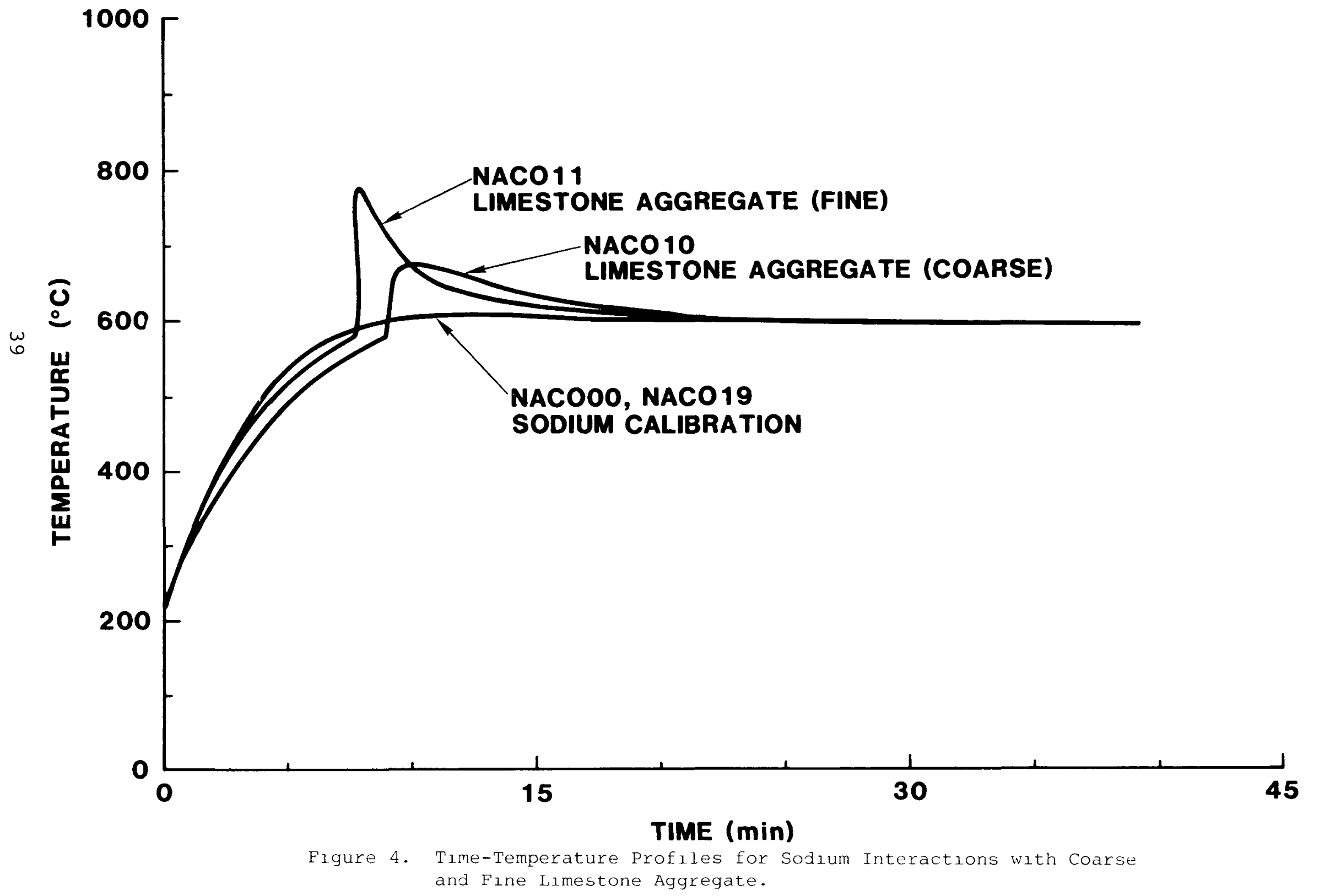




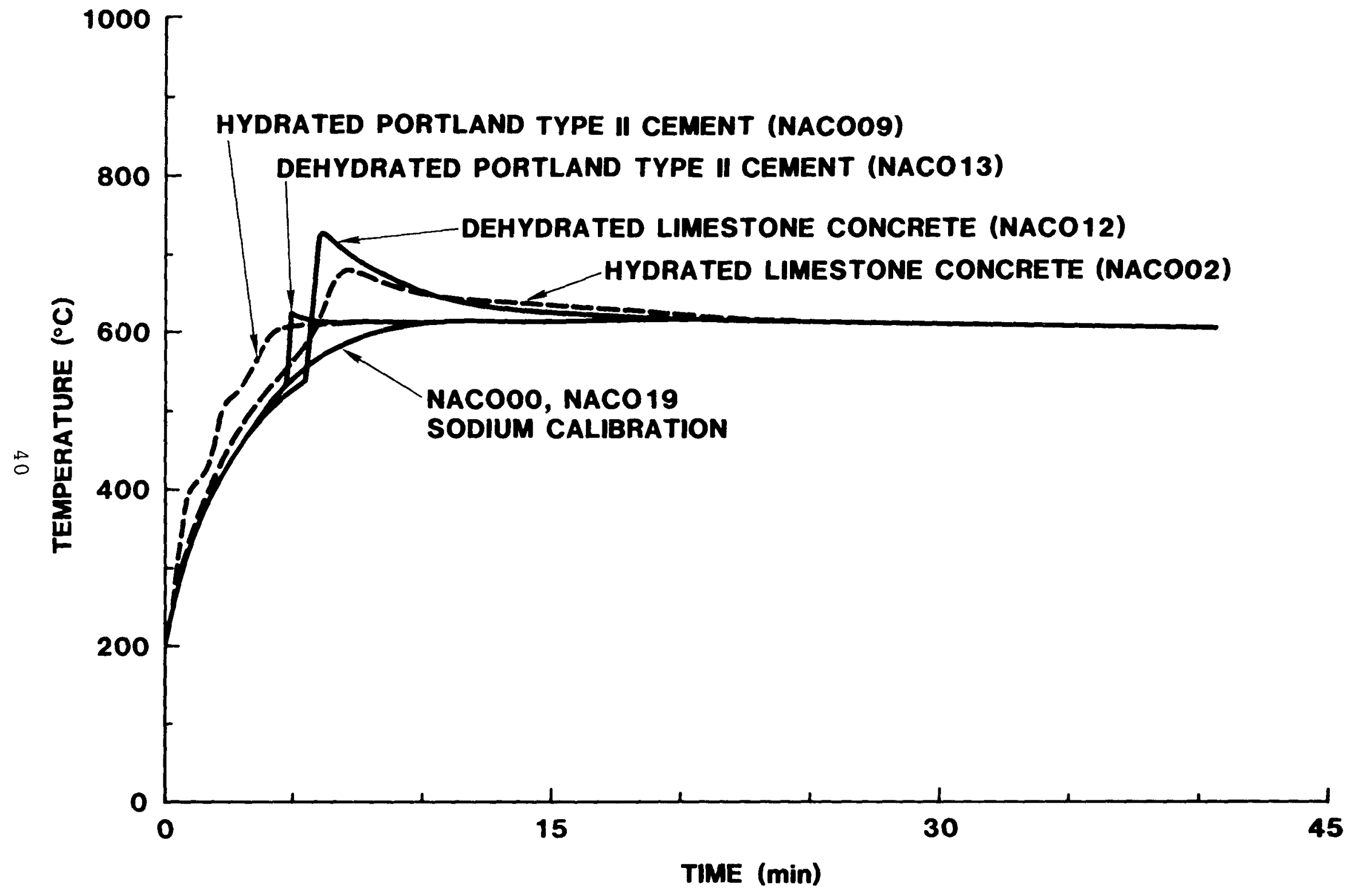

Figure 5. Time-Temperature Profiles for Sodium Interactions with Hydrated

and Dehydrated Limestone Concrete and Portland Type II Cement. 


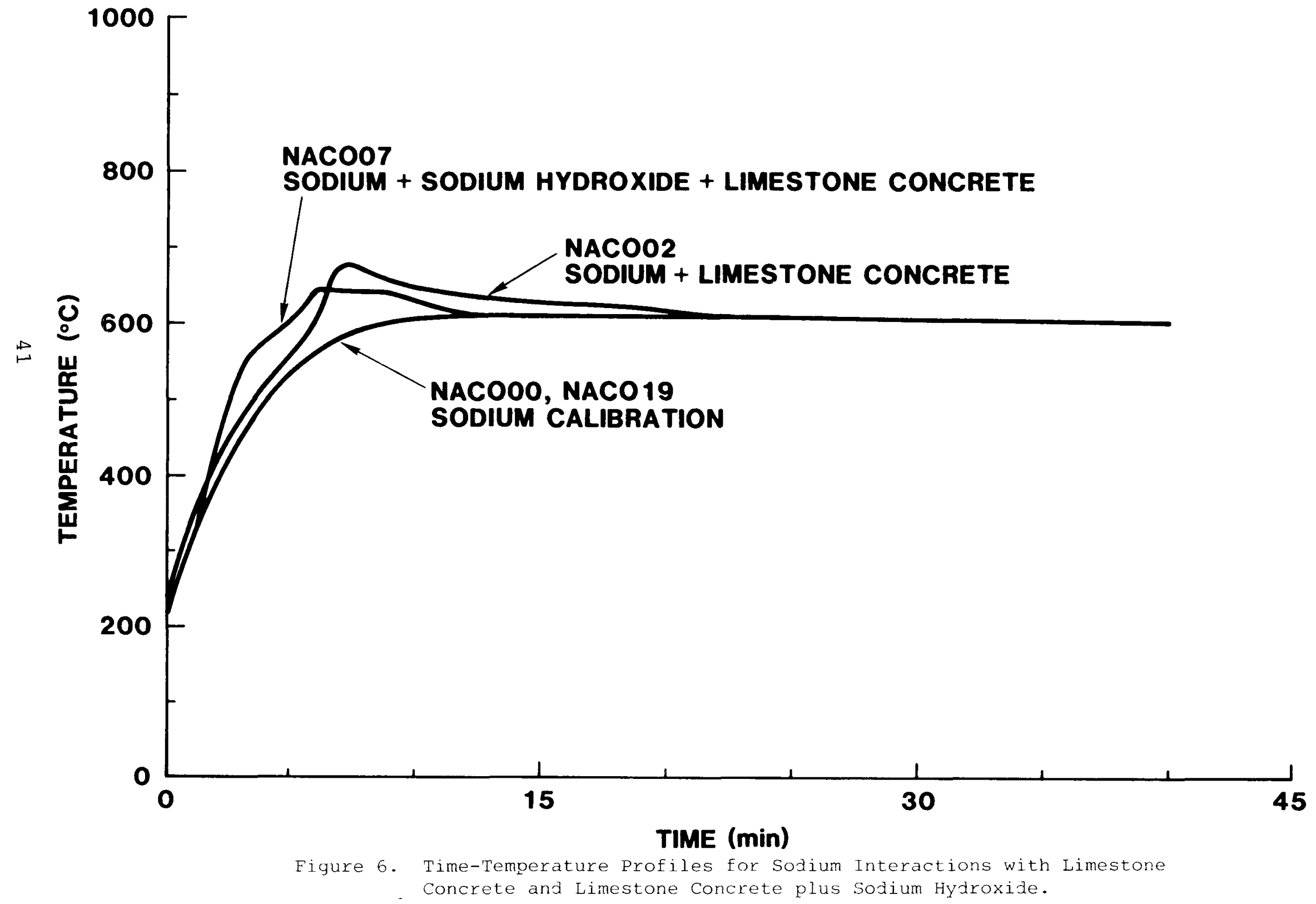




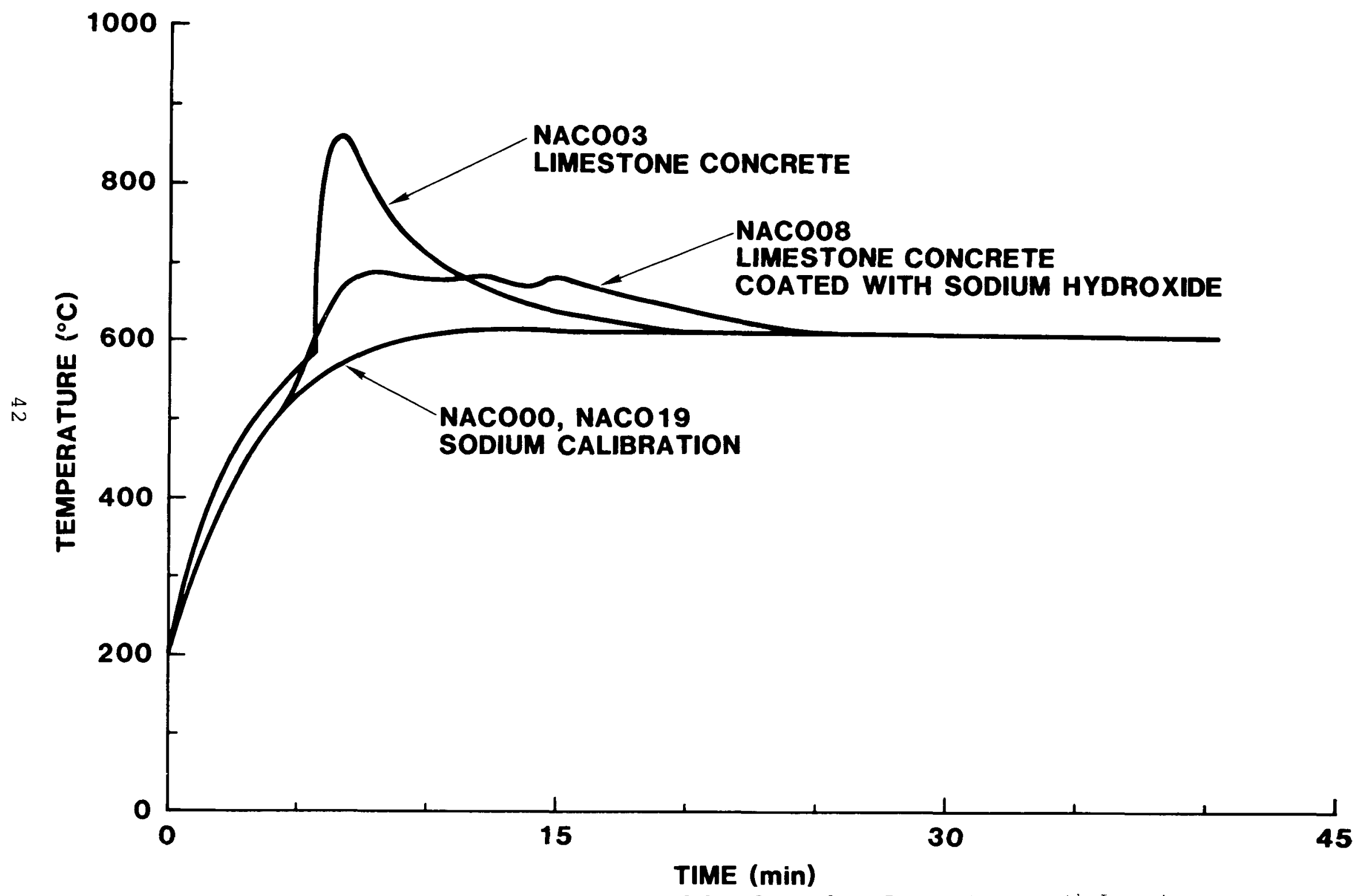

Figure 7. Time-Temperature Profiles for Sodıum Interactions with Limestone Concrete and Sodıum Hydroxide-Coated Limestone concrete. 


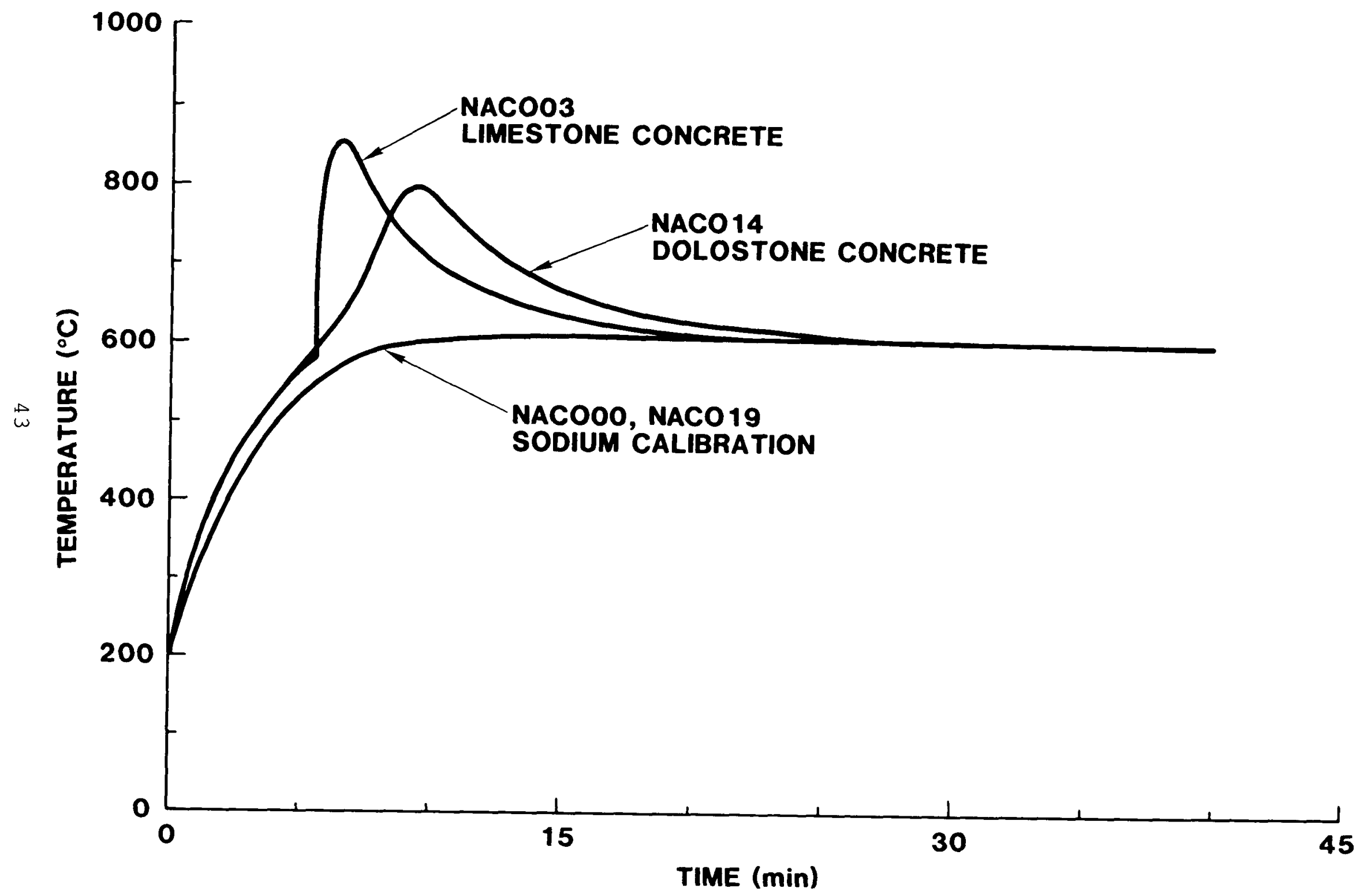

Figure 8. Time-Temperature Profiles for Sodıum Interactions with Limestone and Dolostone Concretes. 


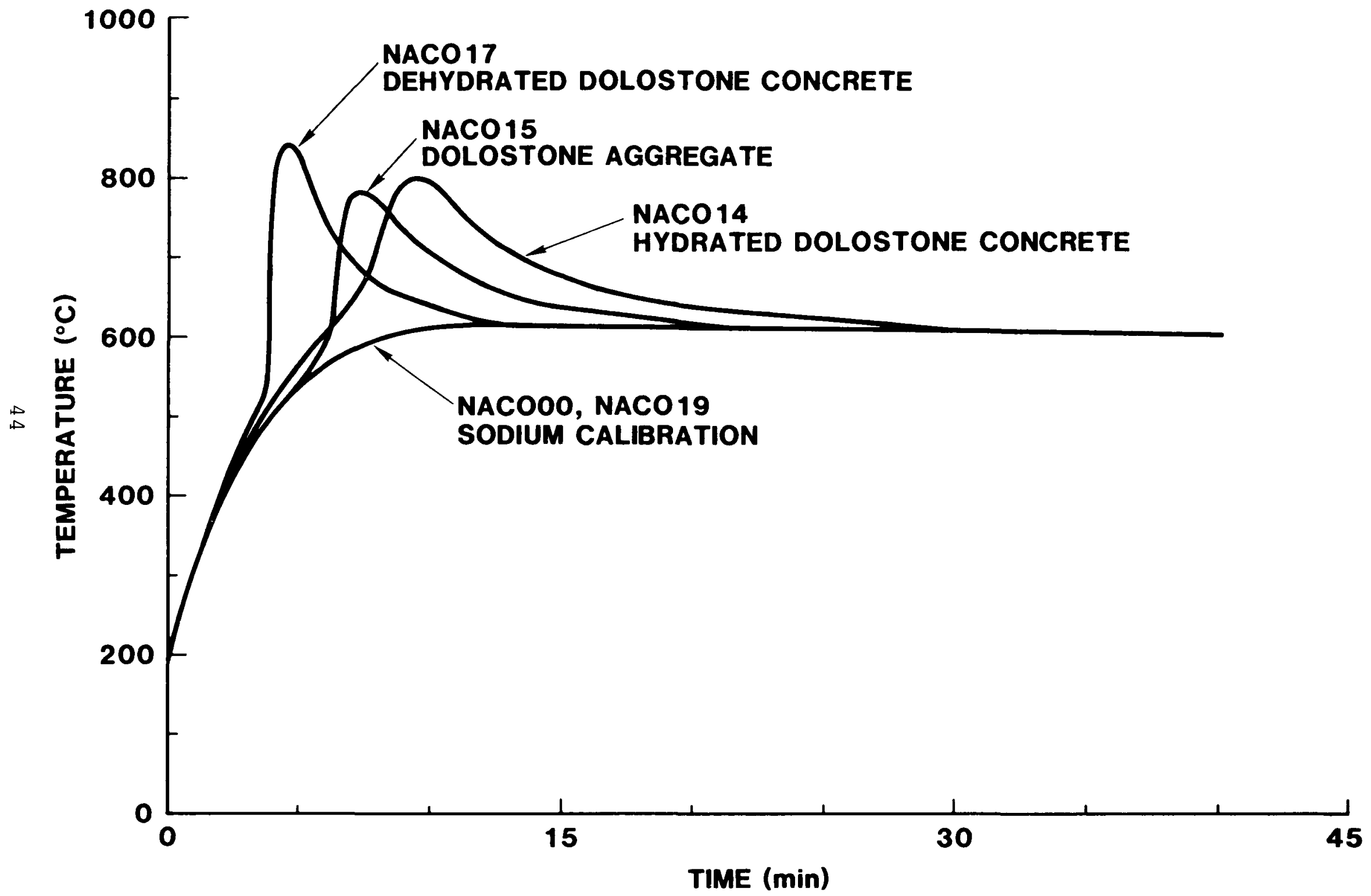

Figure 9. Time-Temperature Profiles for Solium Interactions with Dolostone Concrete, Aggregate and Dehydrated Concrete. 


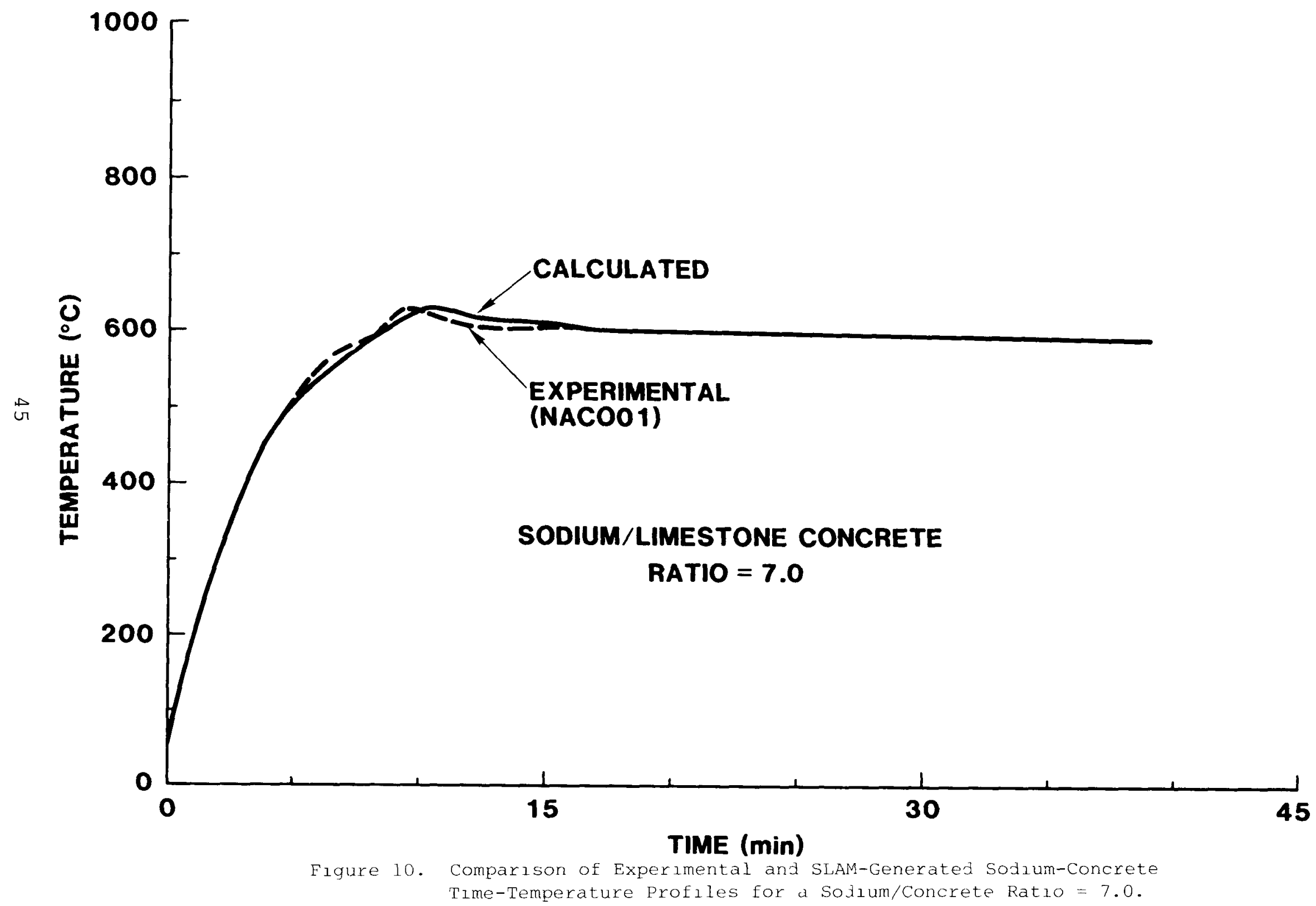




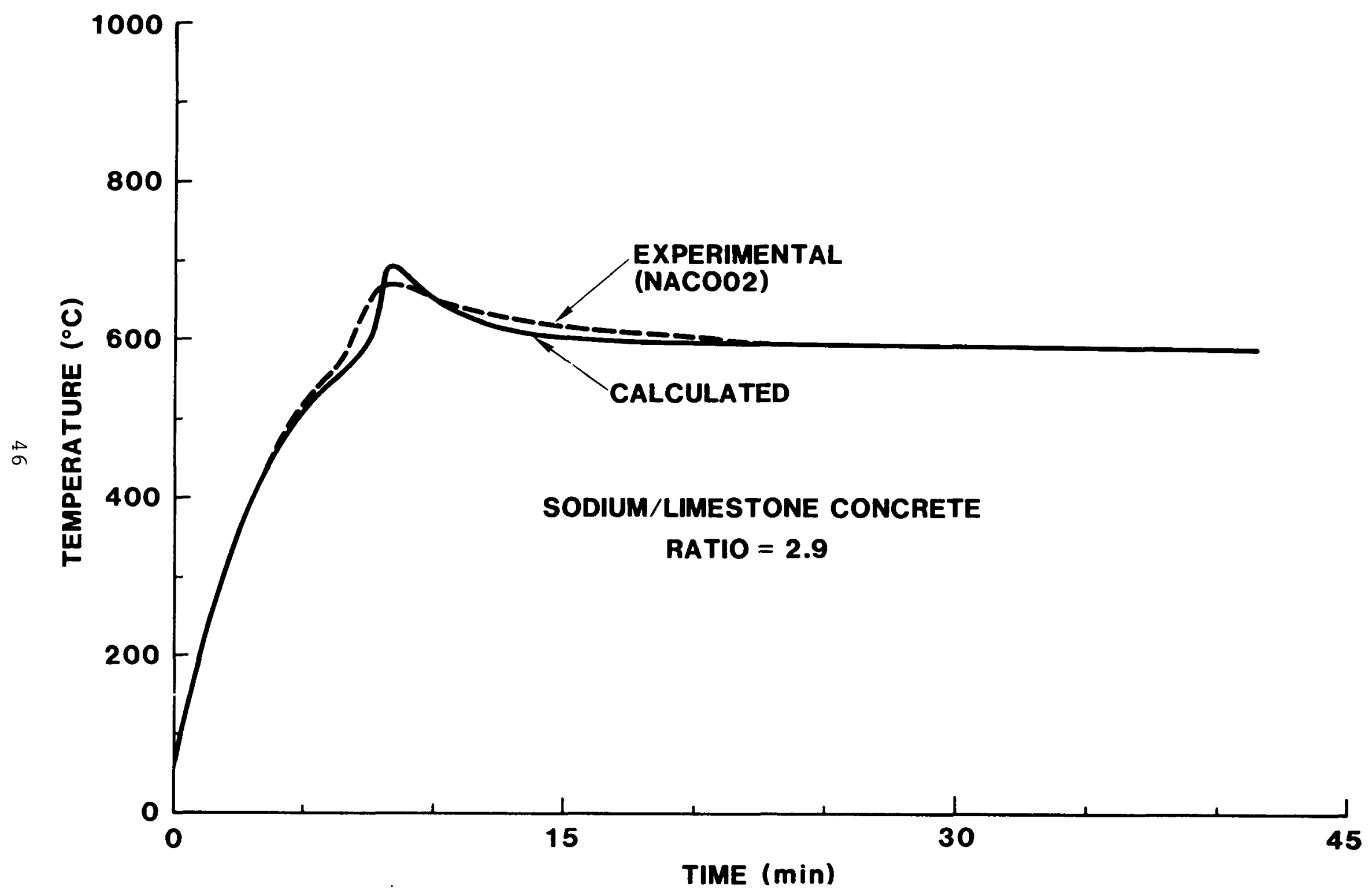

Figure 11. Comparison of Experimental and SLAM-Generated Sodıum-Concrete

Time-Temperature Profiles for a Solıu/Concrete Ratio $=2.9$. 


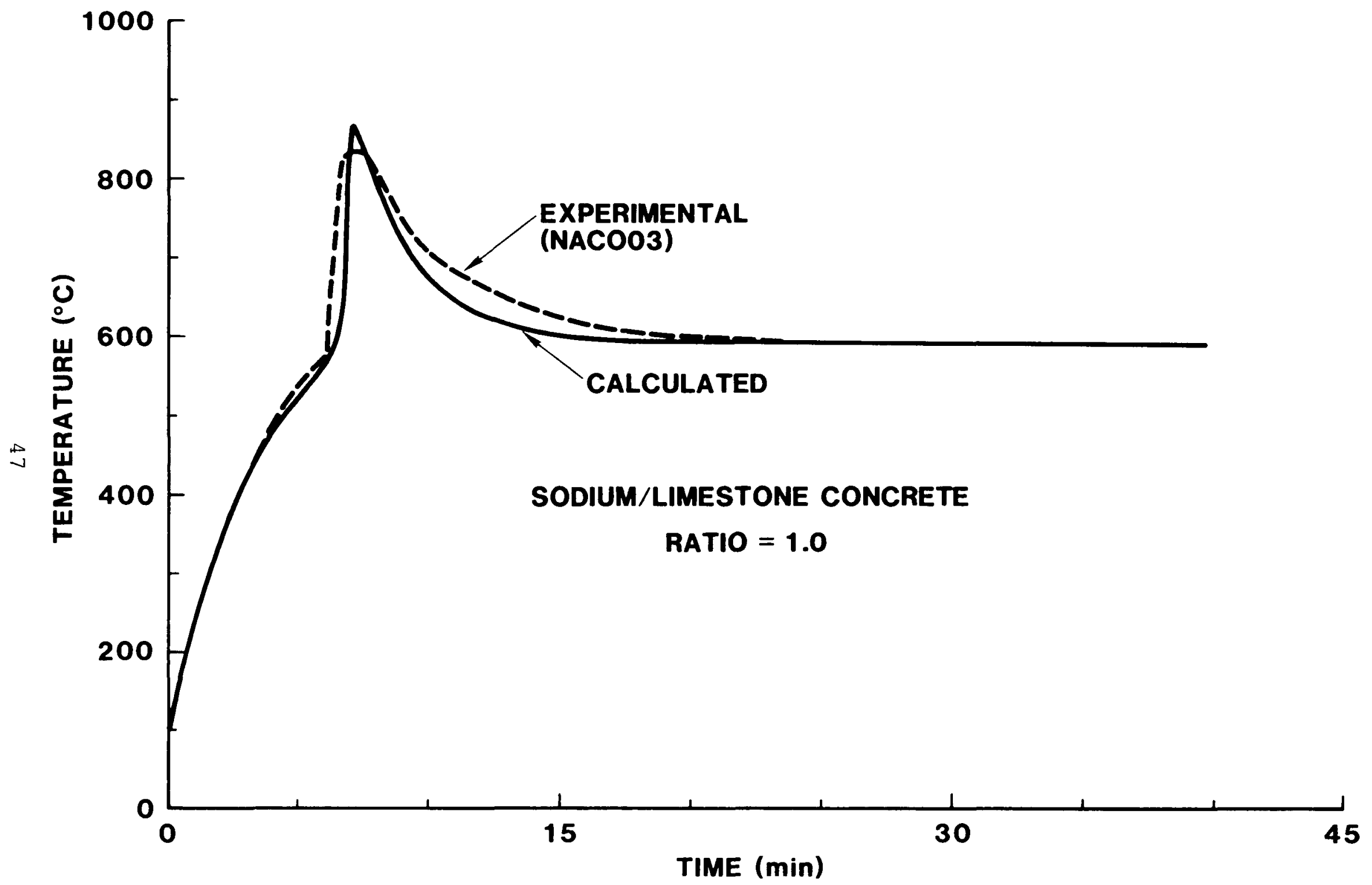

Figure 12. Comparison of Experimental and SLAM-Generated Sodium-Concrete

Tinie-Temperature Profiles for a Sodıum/Concrete Ratio $=1.0$. 


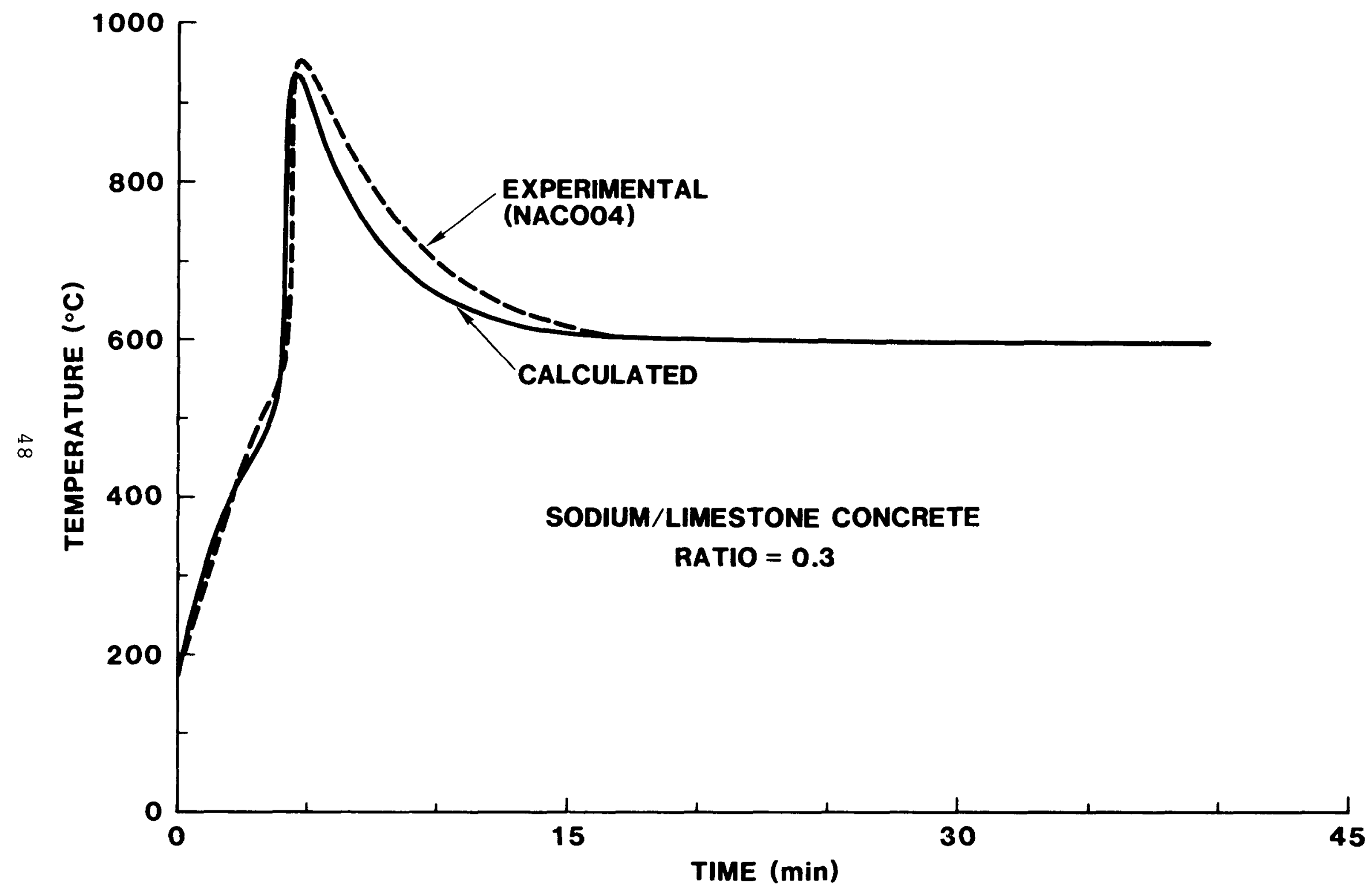

Figure 13. Comparison of Experimental and SLAM-Generated Sodium-Concrete Time Temperature Profiles for a Sodıum/Concrete Ratıo $=0.3$. 


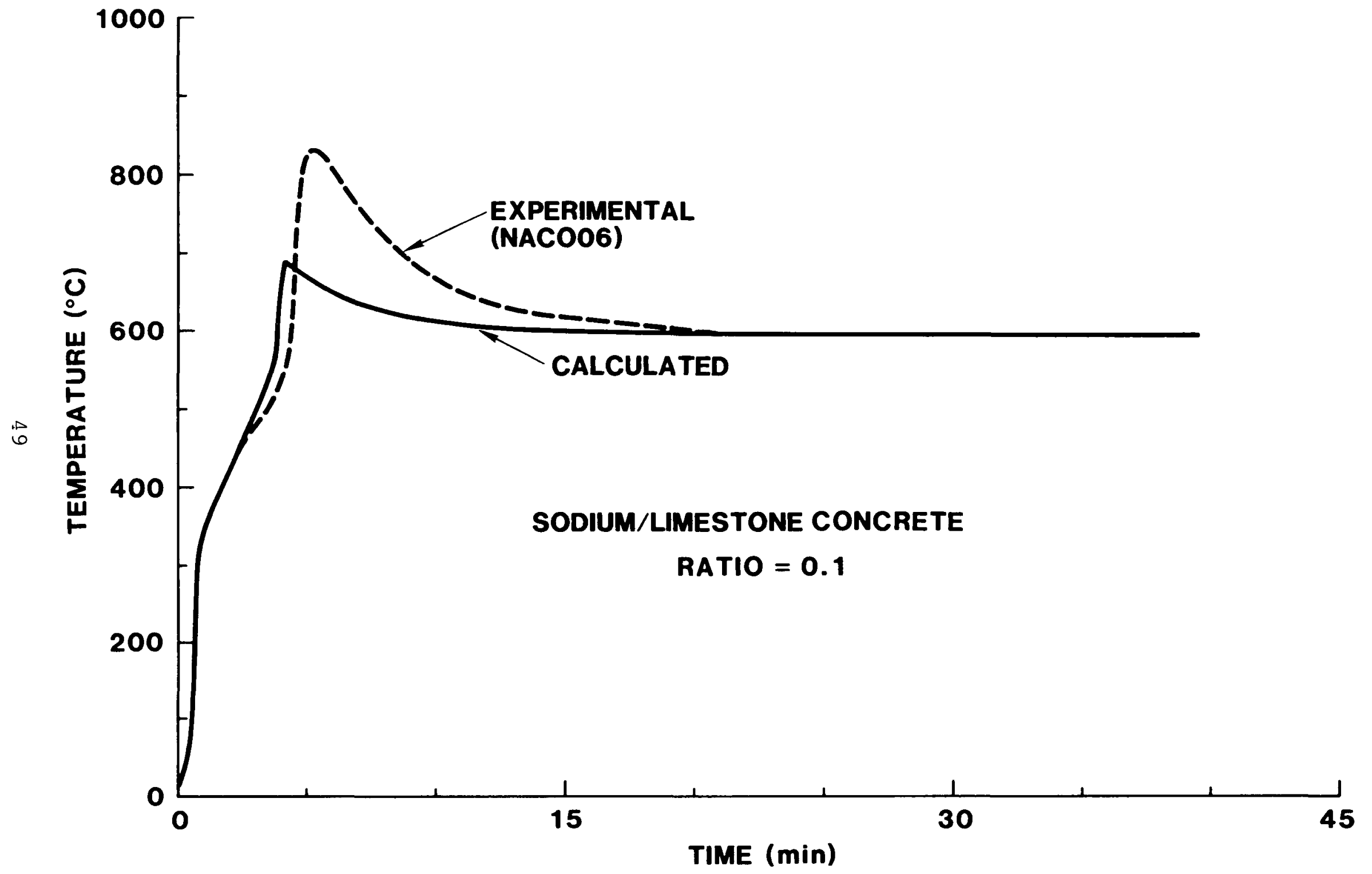

Figure 14. Comparison of Lxperimental and SLAM-Generated Sodium-Concrete

Time-Temperature Profiles for a Sodıum/Concrete Ratıo $=0.1$. 


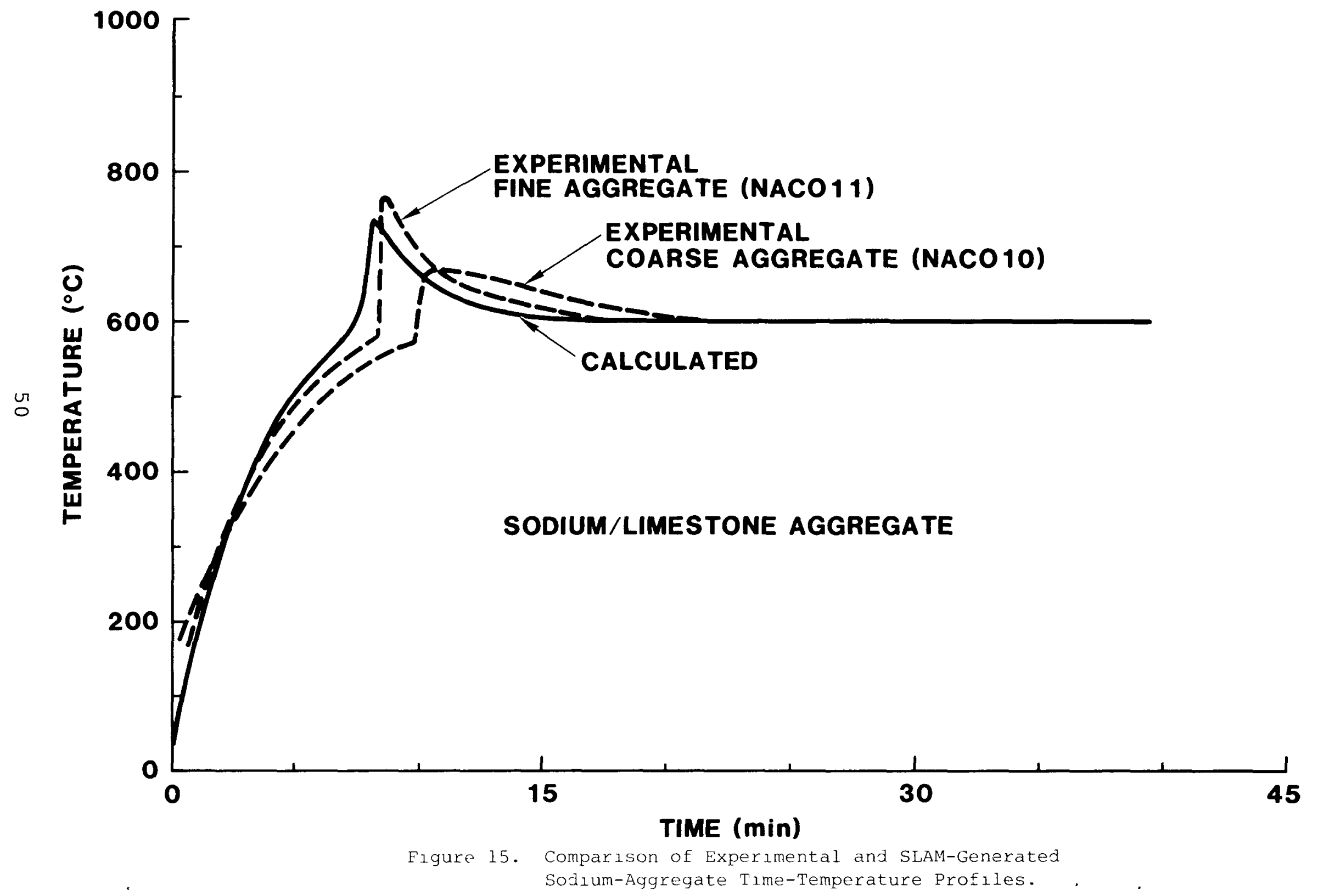




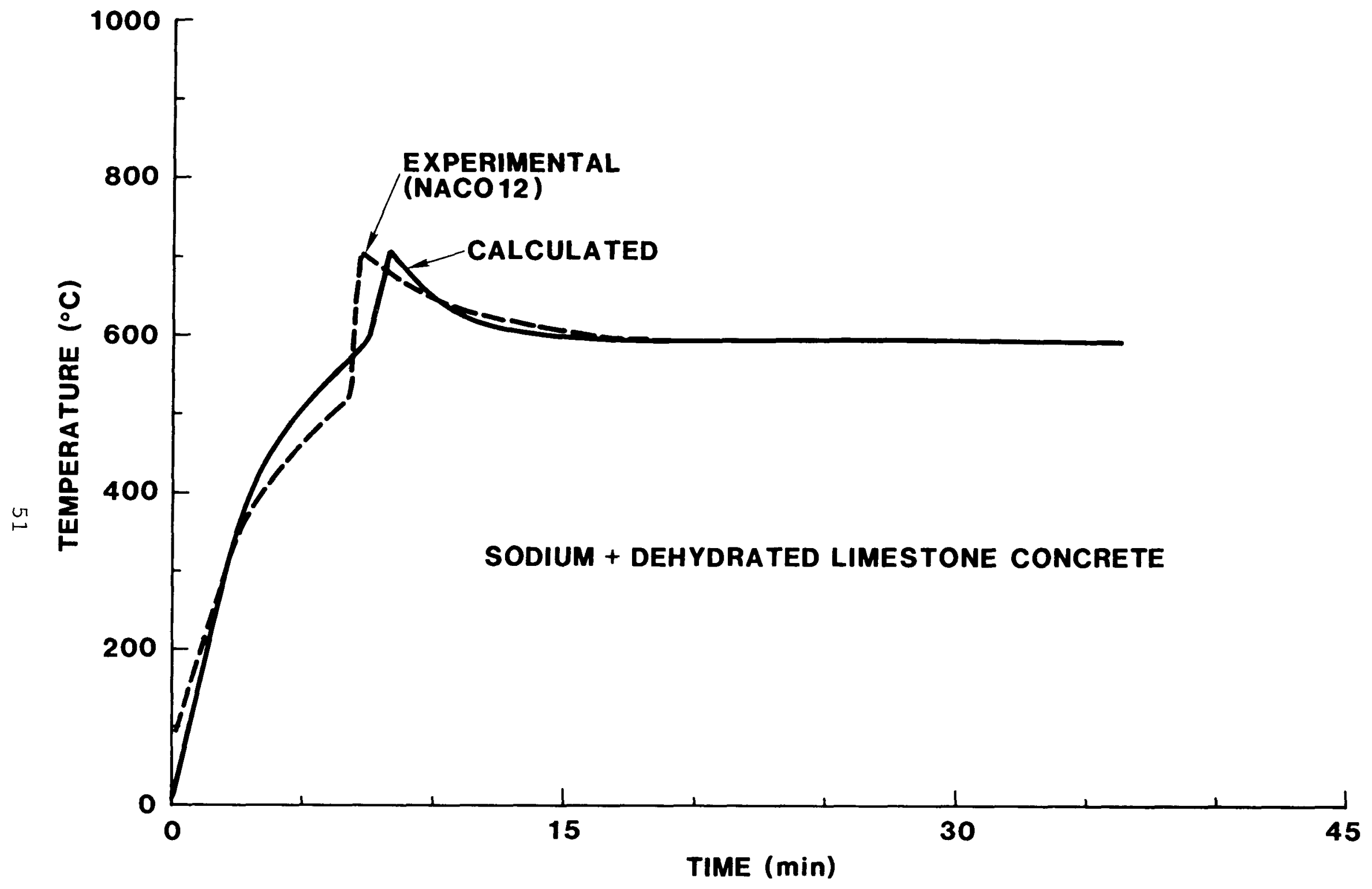

Figure 16. Comparison of Experimental and SLAM-Generated Sodıum-Dehydrated Concrete Time-Temperature Profiles. 


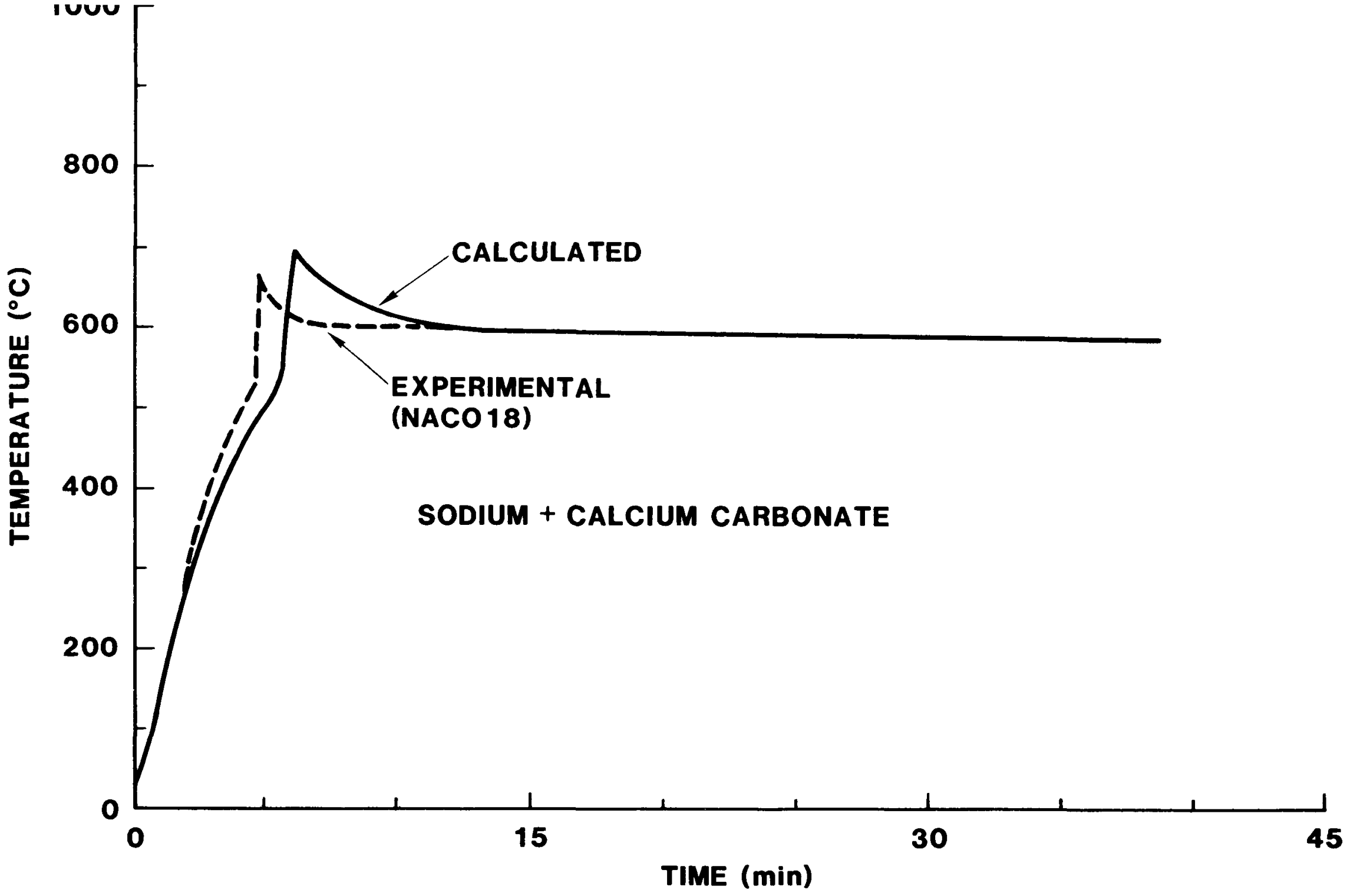

Figure 17. Comparison of Experimental and SLAM-Generated Sołıum-Calcium Carbonate Time-Temperature Profiles. 


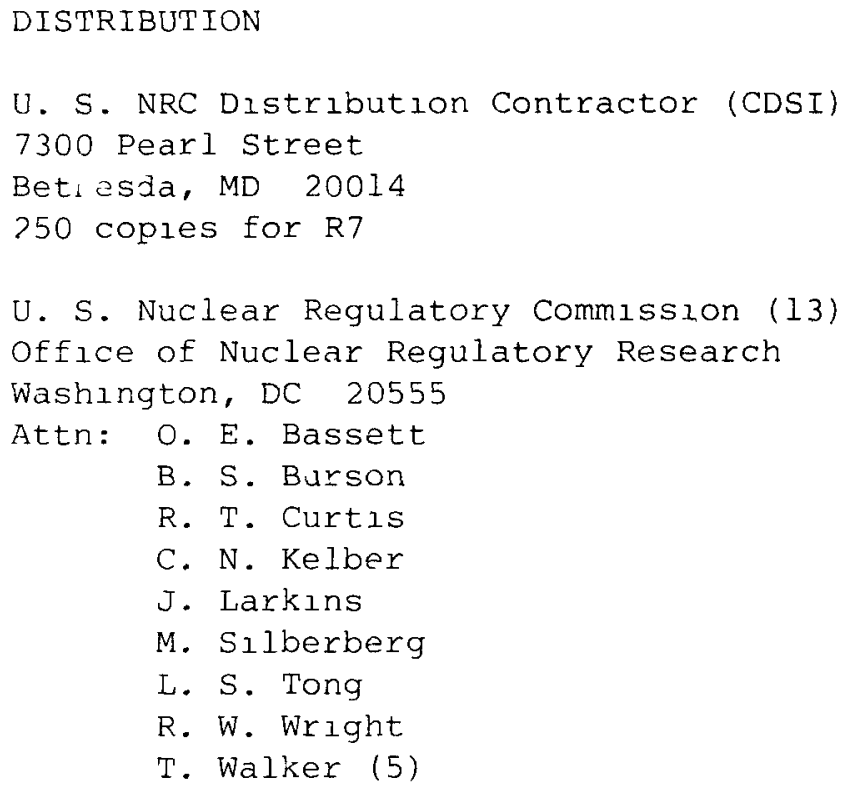

U. S. Nuclear Regulatory Cominssion (6) Office of Nuclear Regulatory Regulation Washington, DC 20555

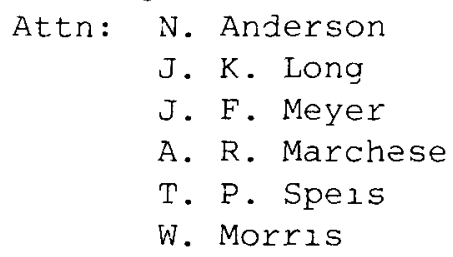

U. S. Department of Energy Office of Nuclear Safety Coordination Washington, DC 20545

Attn: R. W. Barber 
General Electric Corporation (3)

310 De Gulgne Drive

Sunnyvale, CA 94086

Attn: J. W. MeDonald, Mgr.

Containment Radiological Evaluation

M. I. Temme, Mgr.,

Safety Criteria Assessments

K. H. Chen, M/C S-54

W. Tarbell

Ktech Corp.

901 Pennsylvania NE

Albuquerque, NM 87110

I. Catton

UCLA

Nuclear Energy Laboratory

405 Hilgard Avenue

Los Angeles, CA 90024

Brookhaven National Laboratory (3)

Upton, NY 11973

Attn: D. Hsieh

T. Pratt

Los Alamos National Laboratory (3)

P. O. Box 1663

Los Alamos, NM 87545

Attn: T. Butler

D. Jensen

A. Neuls

L. Baker, Jr.

ANL

9700 S. Cass Ave.

Argonne, IL 60439

Burns Roe Industrial Services Corp. (2)

650 Winters Ave.

P. O. Box 667

Paramus, NJ 07652

Attn: A. T. Dajanı

R. E. Palm

Prof. Charles E. Semler, Director

Refractorles Research Center

The Ohio State University

17 Watts Hall

2041 College Road

Columbus, $\mathrm{OH} 43210$ 


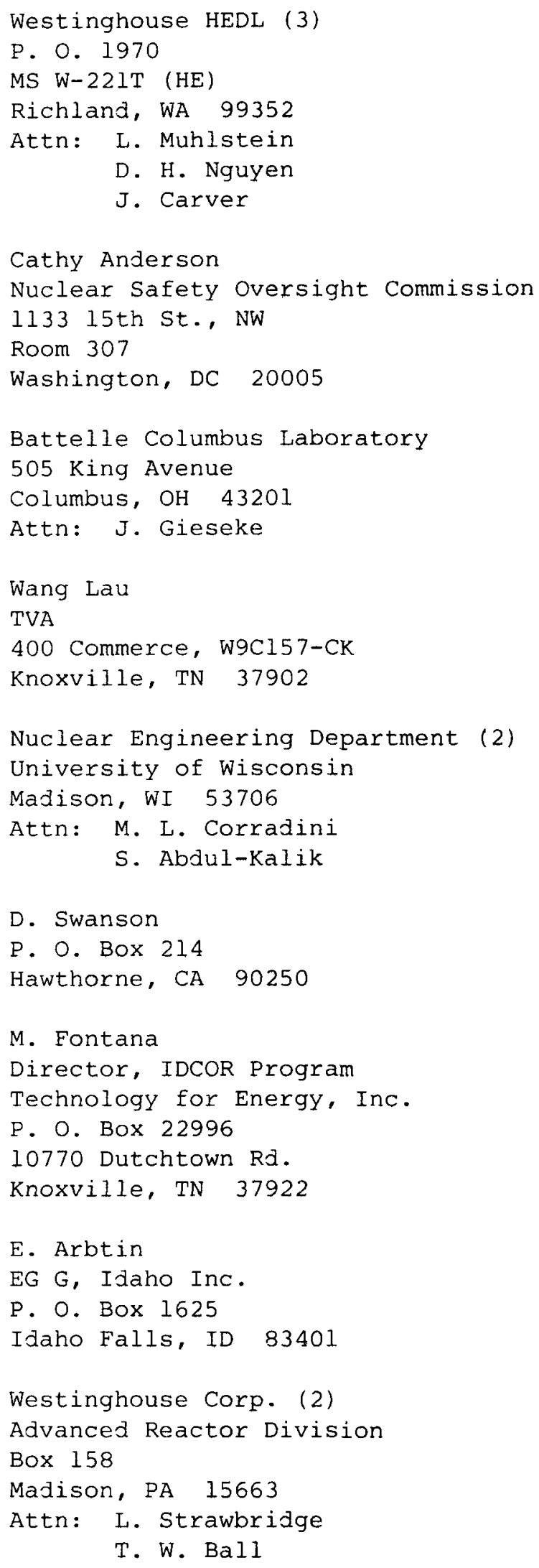




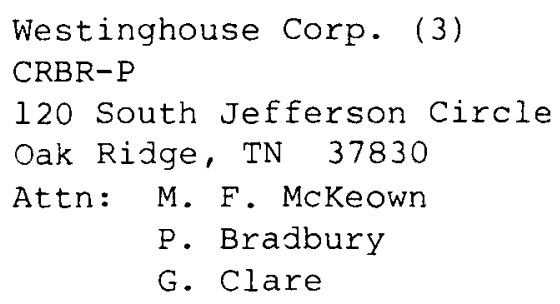




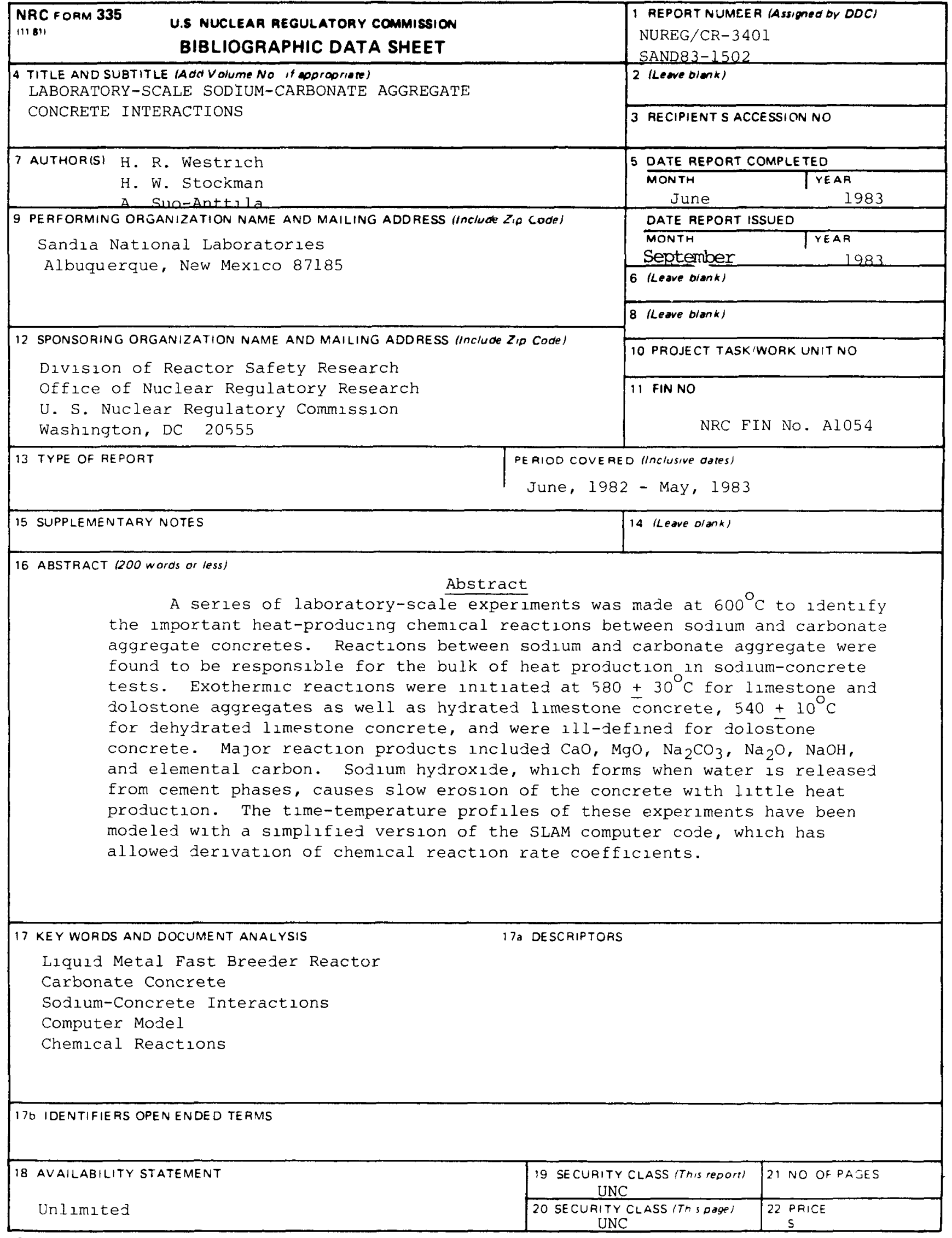

